Journal Of Marine Research

May 2017, Volume 75 Issue 3 Pages 301-329

http://dx.doi.org/10.1357/002224017821836842

http://archimer.ifremer.fr/doc/00410/52106/

(c) 2017 Anne Marie Tregiuer, Eric P Chassignet, Arnaud Le Boyer, and

Nadia Pinardi

\title{
Modeling and forecasting the "weather of the ocean" at the mesoscale
}

\author{
Treguier Anne-Marie ${ }^{1, *}$, Chassignet Eric P. ${ }^{2,3}$, Le Boyer Arnaud ${ }^{4}$, Pinardi Nadia ${ }^{5}$
}

${ }^{1}$ IUEM, CNRS Ifremer IRD UBO, LOPS, CNRS, Rue Dumont dUrville, Plouzane, France.

${ }^{2}$ Florida State Univ, COAPS, Tallahassee, FL 32306 USA.

${ }^{3}$ Florida State Univ, Dept Earth Ocean \& Atmospher Sci EOAS, Tallahassee, FL 32306 USA.

${ }^{4}$ Univ Calif San Diego, Scripps Inst Oceanog, Marine Phys Lab, La Jolla, CA 92093 USA.

${ }^{5}$ Univ Bologna, Dept Phys \& Astron, Bologna, Italy.

* Corresponding author : Anne-Marie Treguier, email address : treguier@ifremer.fr

\begin{abstract}
:
We present a historical perspective on ocean mesoscale variability and turbulence, from the physical basis and the first numerical models to recent simulations and forecasts. In the mesoscale range (typically, spatial scales of $100 \mathrm{~km}$ and time scales of a month), nonlinearity, and energy cascades were well understood in the 1970s, but the emergence of coherent vortices took place much later. New challenges have arisen with the exploration of the submesoscale regime, where frontal dynamics play a key role and the range of flow instabilities is wider than in the quasi-geostrophic regime. Special focus is placed on the interaction of mesoscale turbulence with the continental slopes. The contrast between the variability on the western and eastern boundaries of an ocean basin is illustrated by numerical simulations of the North Atlantic. On the eastern continental slope, direct forcing of currents by wind fluctuations is more important than it is on the western side of the basin, where forcing by intrinsic mesoscale variability is dominant. Dynamical characteristics of the ocean mesoscale such as these must be taken into account in building forecasting systems. These systems require improved numerical models to represent mesoscale variability with more fidelity. We present our view of the most pressing needs for model development as they relate to the challenges of data assimilation at the mesoscale.
\end{abstract}

Keywords : Numerical model, ocean forecast, ocean mesoscale turbulence 


\section{1 - Introduction}

Fifty years ago, scientists could only get a glimpse of the ocean's mesoscale motions through sparse in situ measurements. While oceanographers have since realized that the ocean is fully turbulent, it was not until the 1970 s with the advent of satellites that they were able to fully recognize the omnipresence of oceanic eddies. The main currents contributing to the "general circulation" of the ocean, such as the Gulf Stream or the Antarctic Circumpolar Current, are unsteady and display strong variability in the form of propagating waves, meanders, and eddy shedding. The ocean's mesoscale is characterized by space scales much smaller than ocean basins, from about $10 \mathrm{~km}$ to several hundreds of $\mathrm{km}$, and time scales shorter than seasonal but longer than inertial (typically one month). Variability is larger than the time-mean in this frequency band, which is often the most energetic in the ocean. Today, the beauty and complexity of these mesoscale features can be seen by all by viewing movies made from high resolution satellite images or numerical model simulations (Chelton et al., 2011). It is fascinating to watch currents meander and shed eddies, eddies merge or split, and unstable waves develop, propagate and decay. A surface velocity snapshot in an eddying model (Drakkar $1 / 12^{\circ}$ model, Treguier et al., 2014) illustrates the complexity of the global eddy field (Figure 1).

Up to the seventies, mesoscale eddy signals were biased by incomplete and inadequate data sets; the MODE (MODE Group, 1979) and then POLYMODE experiments (McWilliams et al., 1986) clarified the thermohaline structure and the horizontal correlation scales of the mesoscales for the first time. Results from these experiments are still at the basis of our understanding of ocean mesoscales. A comprehensive book edited by Robinson (1983) overviewed the mesoscale observational evidence and the modeling strategy to be adopted in order to resolve eddies in the ocean.

Mesoscale eddies play a fundamental role in controlling the strength of mean currents and in transporting heat, salt, and biogeochemical tracers between latitude bands and between ocean basins. The mesoscale also poses the main challenge for operational forecasts. A recent example is the 2010 Deepwater Horizon oil spill where an accurate prediction of the position of a recently formed Gulf of Mexico Loop Current eddy was essential in determining if much of the spilled oil would remain within the Gulf or be advected into the Florida Current and ultimately the Atlantic Ocean (Adcroft et al., 2010).

The ocean mesoscale is often described as the "weather" of the ocean, equivalent to the synoptic variability in the atmosphere. It shares many characteristics with atmospheric weather. Nonlinearity and sensitivity to initial conditions make it difficult to predict. The chaotic behavior of the ocean mesoscale results in large differences between forced ocean simulation with slightly different initial conditions and marginally different atmospheric forcing fields when no data assimilation is used. This "intrinsic variability" of the ocean has been documented recently using long simulations forced by a repeated seasonal cycle of atmospheric data (Penduff et al., 2011; Serazin et al., 2015). Overall, our understanding of the fundamental dynamics underlying the ocean mesoscale has progressed considerably over the past several decades, as has our ability to produce realistic numerical simulations of these dynamics. 
This paper presents the main characteristics of mesoscale variability in the ocean from a historical perspective, from the physical basis and the first numerical models to recent progress in simulations and forecasts. This subject is vast and this paper is, out of necessity, limited in its scope. We have chosen to concentrate on a few essential physical processes that we believe must be taken into account for the fidelity of simulations and the design of successful forecasting systems.

\section{2 - Dynamical regimes and origin of the mesoscale variability}

Earth rotation and vertical stratification are the two main physical parameters influencing mesoscale variability in the ocean. In the mesoscale regime, the Coriolis frequency $f$ must be taken into account and the Rossby number $R o$ is small: $R o=U / f L=$ $O\left(10^{-2}\right)$, for typical velocities $U$ of $0.1 \mathrm{~m} / \mathrm{s}$ and spatial scales $L$ of $10 \mathrm{~km}$. This means that, at the first order, the flow obeys the geostrophic relation and the horizontal velocity, being non-divergent, is described by a stream function $\psi$. A simplified system of equations, the quasi-geostrophic (QG) equations, can be derived by further assuming a small aspect ratio $H / L$ ( $H$ being the ocean depth) and a small Froude Number $F r=U / N H$, $N=-\frac{g}{\rho_{0}} \frac{\partial \rho}{\partial z}$ being the buoyancy frequency given by the time and horizontally averaged stratification $\rho(z)$.

Within this parameter regime, the QG prognostic equation for the relative vorticity,$\nabla^{2} \psi$, is obtained by taking the curl of the horizontal momentum equations. The vertical dimension of the flow field can be described either by a superposition of layers at different densities, or by a decomposition into vertical modes structured by the stratification. In both cases, the barotropic stream function describes the depthintegrated transport, and the flow field is the sum of the barotropic and baroclinic modes. In a continuously stratified ocean, the QG potential vorticity equation can be written in the compact form

$$
\begin{gathered}
\frac{d q}{d t}=G+D \\
q=\nabla^{2} \psi+f+\frac{\partial}{\partial z}\left(F \frac{\partial \psi}{\partial z}\right)
\end{gathered}
$$

where $\frac{d}{d t}=\frac{\partial}{\partial t}+J(\psi$,$) is the total derivative and J$ is the Jacobian, $F=\frac{f_{0}^{2}}{N^{2}}$ is the stretching parameter, $G$ represents the forcing, and $D$ the dissipation. Note that the variation of $f$ with latitude, the $\beta$-effect, has to be taken into account in the mesoscale regime for a realistic representation of eddy anisotropy and westward propagation.

The fundamental principles of mesoscale dynamics have been established using this powerful quasi-geostrophic framework, both in the linear (wave) regime and in the nonlinear regime. The free solutions of the linear QG equations in an unbounded domain are westward propagating Rossby waves. However these waves are unstable (infinitesimal disturbances lead to large disturbances), which means that nonlinearity can seldom be ignored. Numerical solutions of the QG system in its simplest form, the 
two-dimensional (2D) barotropic equation, made the first successful atmospheric weather forecasts possible (Charney et al., 1950). Numerical solutions of the QG equations in their baroclinic form later demonstrated the feasibility of oceanic forecasts at the mesoscale (Robinson et al., 1984).

The key to understanding mesoscale variability lies in the theory of baroclinic instability, which was established in the early 1950s by Charney (1947) and Eady (1949), who demonstrated that a vertically sheared current can feed mesoscale disturbances. When the mean flow is baroclinically unstable, small perturbations grow by tapping into the available potential energy, which is related to the vertical shear of geostrophic currents (the well-known "thermal wind" balance). Baroclinic instability is the source of synoptic disturbances in the atmosphere as well as the source of the most energetic mesoscale structures in the world ocean. Because it involves a characteristic scale, the Rossby radius of deformation $\left(R_{d .}\right)$, this powerful theory explains why so much energy is found at the mesoscale (at midlatitudes, the peak in energy density at wavenumbers of order $30-50 \mathrm{~km}^{-1}$ has been described using satellite altimetry data, see for example Scott and Wang, 2005). In a baroclinically unstable flow, the maximum growth rate for a linear perturbation is achieved at a scale related to $R_{d}$. With constant stratification $N$ and water depth $H$, the first internal Rossby radius is given by $R_{d}=N H / \pi f$. It is the characteristic scale of the first baroclinic mode, which has the largest vertical scale: the velocity profile has only one zero-crossing at mid-depth. For an arbitrary stratification $N(z)$ the Rossby radii are the eigenvalues of a Sturm-Liouville equation. The first Rossby radius varies from more than $200 \mathrm{~km}$ in the tropics to $20 \mathrm{~km}$ at $50^{\circ}$ and just a few kilometers in the weakly stratified polar regions or on the continental shelf (Chelton et al., 1998). Higher baroclinic modes have smaller vertical scales and smaller Rossby radii.

In many regions of the world ocean the vertical shear associated with the main thermocline is the largest source of baroclinic instability and thus mesoscale energy. This explains why the first Rossby radius $R_{d}$ is a relevant scale for the mesoscale flows we observe. An example of this "scale selection" process, by which a dominant spatial pattern emerges from a wide spectrum of random perturbations, is provided in Figure 2 in the case of a baroclinically unstable two-layer channel flow. Starting from a random pertubation, which is clearly visible in the lower layer because the mean streamfunction is initially zero there, the wave with wavelength $1 / 3$ of the channel length grows with the fastest rate and becomes dominant. At day 400 and later, the flow becomes nonlinear: a cascade towards larger scales and barotropization occurs. Note that such a two-layer model is a very crude representation of the vertical structure of the ocean. In the case of complex vertical shears (in the presence of a seasonal thermocline or with strong surface intensification), higher baroclinic modes have the largest growth rate (Smith and Vallis, 2002). In these cases, accurate numerical simulations and forecasts require a horizontal and vertical resolution substantially higher than the one suggested by the first baroclinic Rossby radius alone.

A horizontally sheared geostrophic current is also subject to instability (Kuo, 1949); the shear instability at the mesoscale, where the $\beta$-effect is important, is called barotropic instability. Contrary to baroclinic instabilities, which feed on the available potential energy of the mean flow, barotropic instabilities grow from the mean kinetic energy. In reality, ocean current instabilities are often mixed (baroclinic and barotropic, Killworth, 
1980) with both the mean available potential energy and the mean kinetic energy being the main sources of eddies in different regions or at different times.

In uniform zonal flows there is a critical value of the vertical current shear below which the flow is stable (Pedlosky, 1987). However, this is not the case for meridional sheared flows. As a consequence, except for a few locations where a strong bathymetric gradient may stabilize a current flowing parallel to the slope, ocean currents are baroclinically unstable everywhere in the global ocean (Smith, 2007). This explains the ubiquity of mesoscale turbulence in the ocean. Of course other mechanisms, such as atmospheric synoptic variability, can force mesoscale motions (Treguier and Hua, 1987). Wind patterns in the lee of islands can also induce the generation of coherent mesoscale eddies (Chelton et al, 2011).

The most revealing maps of mesoscale eddy activity have been obtained by satellite altimetry (a recent review is provided by Morrow and Le Traon, 2012). As expected, because it results from flow instabilities, the surface eddy kinetic energy displays the same inhomogeneity as the time-mean ocean circulation. There are regions of high eddy activity near strong currents, such as the Gulf Stream, the Kuroshio, the equatorial currents, and the Antarctic Circumpolar current. Mesoscale motions exist in a variety of forms: meanders develop, sometimes leading to the formation of detached eddies or rings; isolated eddies coexist with zonal jets and wavelike motions. All of these features are well reproduced by eddying models, the snapshot of velocity in Figure 1 being an example. Moreover, there is no spectral gap on either side of the mesoscale band, neither in frequency nor in space. Mesoscale flows are part of a continuous spectrum of ocean turbulence, ranging from the basin scale to submesoscale filaments and internal waves.

\section{3 - Nonlinearity, energy cascades, and submesoscales}

In this special issue of the Journal of Marine Research "The Sea", it is important to recall the remarkable contribution of Peter Rhines nearly fourty years ago, in The Sea volume 6 entitled "The dynamics of unsteady currents," in which he reviewed extensively the then current knowledge about mesoscale dynamics (Rhines, 1977). Like purely twodimensional turbulence, quasi-geostrophic flows exhibit an inverse energy cascade towards larger scales (Charney, 1971). Rhines (1975) demonstrated by a dimensional analysis of the QG equations, and confirmed by numerical experiments, that the nonlinear cascade is halted by Rossby wave propagation near the meridional wavenumber $K_{p}$, where $K_{p}=(\beta / U)^{1 / 2}$. Rhines' numerical experiments were the first to show that the nonlinear cascade led to the emergence of zonal jets resulting from the $\beta$ effect's influence on the inverse cascade (Figure 3). Rhines (1977) also presented evidence for zonal jets from observations, which were still sparse at the time. Such jets have since been observed in deep ocean basins (Hogg and Owens, 1999), reproduced in numerical models (Treguier et al, 2003), and observed by altimetry at the surface (Maximenko et al., 2005) as well as by Argo floats at depth (Ollitrault and Colin de Verdière, 2014).

Rhines also demonstrated numerically the inverse cascade of energy in the vertical dimension, which had been inferred theoretically by Charney (1971). Baroclinic 
mesoscale motions corresponding to high vertical modes (i.e., having complex smallscale vertical structures) tend to lose energy to lower vertical modes and ultimately to the barotropic mode (Charney 1971). This "barotropization" process is very efficient: in Rhines' numerical experiments with only one baroclinic mode (two layers model), the flow becomes predominantly barotropic in a few eddy turnover times (a few months). This cascade on the vertical is slowed by the presence of bottom topography.

These fundamental characteristics of QG turbulence must be kept in mind when trying to perform accurate ocean forecasts. The evolution of ocean currents, even at the surface, cannot be modelled without an adequate representation of barotropicbaroclinic coupling and an accurate bottom bathymetry.

Rhines (1977) then considered wave-mean flow interactions. Based on linear theory, a westward jet is more unstable than an eastward jet: in a two-layer model with layers of unequal depth, the eastward surface jet is not unstable unless the vertical current shear is above a higher critical value (Pedlosky, 1987). Considering Rossby wave propagation radiating away from a jet, Rhines demonstrated that the eddy flux of momentum strengthens an eastward jet. This "negative viscosity" effect has strong implications for ocean forecasting. The equilibrium of a mean jet results from a balance of eddy dissipation and eddy rectification, therefore a complete description of the mesoscale eddy field near a strong current is needed to predict its evolution. The capacity of eddies to generate time-mean currents is especially strong in the presence of bathymetry. Building on the work of Bretherton and Karweit (1975), Rhines presented numerical solutions of free decaying QG turbulence over topography, showing the generation of mean circulations along the $f / h$ contours. This rectification effect was later referred to as the "Neptune effect" by Holloway (1992). It plays a major role in ocean circulation: for example, it is responsible for the existence of the Zapiola Anticyclone, a gyre circulation in the Argentine basin that is stronger than the Gulf Stream (de Miranda et al., 1999).

Although very rich, the vision of mesoscale turbulence conveyed by Rhines (1977) was missing a key ingredient: isolated vortices. Detailed observations of coherent structures in the ocean during the 1970s motivated new theoretical and numerical investigations. Coherent vortices are nonlinear, which allows them to persist for long periods of time (many months to years) contrary to linear Rossby wave packets, which disperse rapidly. Their rotation speed is superior to their translation speed, allowing them to trap properties in their core. McWilliams and Flierl (1979) described thoroughly the propagation of a QG vortex on a $\beta$ plane: all vortices propagate to the west, with typical translation velocities of a few $\mathrm{cm} / \mathrm{s}$. Anticyclones also move equatorward while cyclones move poleward. Vortices arise spontaneously in decaying geostrophic turbulence (Mc Williams, 1989): it was not until the 1980s, when numerical simulations reached a resolution fine enough to represent the dynamics of vortex-vortex interactions, that this fact could be observed. Figure 4 contrasts the vorticity field from one of Rhines' simulations with a recent simulation at high resolution, where most of the vorticity is concentrated in isolated coherent structures after a time of approximately one year. Lahaye et al. (2012) used a shallow water model to investigate the emergence of coherent structures at high Rossby numbers and their interaction with gravity waves. These issues are not yet well understood although they are key elements of the life cycle of ocean eddies. In addition to the inverse cascade, coherent vortices can be generated via barotropic and baroclinic instabilities of larger scale flows, for example rings 
resulting from the "pinching off" of large meanders (Gulf Stream, Kuroshio) or rings spun off by currents changing direction (Agulhas retroflection, North Brazil current) (see Carton (2010) for a review). Topographic effects can also trigger generation of coherent, isolated eddies (Huppert and Bryan, 1976).

Our knowledge of nonlinear mesoscale eddies has progressed considerably thanks to global satellite observations of the sea surface height (SSH). Chelton et al. (2011) analyzed a 16-year global dataset of SSH variability, detecting and tracking 35,891 eddies with lifetimes longer than 16 weeks. They confirmed that midlatitude mesoscale motions are predominantly nonlinear and that eddies are generated everywhere, even in relatively quiescent eastern ocean basins. It is quite remarkable that many of the observed properties of these eddies (size and shape, propagation, lifetime) can be reproduced by a nonlinear QG model (Early et al., 2011).

The QG theory breaks down near strong currents, where the Rossby number becomes large. QG does not allow for bathymetric features comparable to the ocean depth, density gradients at the surface, or frontal dynamics. It also does not distinguish between anticyclones and cyclones, which have different westward propagation speeds (Cushman-Roisin et al., 1990). This is the reason why primitive equation models have replaced QG models for operational applications. Accurate forecasting requires good modeling of the frontal dynamics that cause the asymmetry between cyclones and anticyclones. Anticyclones tend to be more stable than cyclones at a high Rossby numbers (Olson, 1991). On the other hand, frontal dynamics near the surface favors the generation of cyclonic filaments through frontal instability. These, in turn, can roll-up and generate larger scale cyclones by inverse cascade. As a result, ocean turbulence cyclonic vortices tend to dominate near the surface and anticyclonic vortices are more abundant at depth (Roullet and Klein, 2010).

The submesoscale regime is characterized by space scales between $1-10 \mathrm{~km}$ and by order one Rossby and Richardson numbers (Thomas et al., 2008). At the submesoscale, frontogenesis (intensification of fronts due to convergence in the flow) plays a key role and generates high vertical velocities with a strong impact on marine ecosystems (Mahadevan and Tandon, 2006). Mixed layer dynamics at the submesoscale are complex, as three instability mechanisms compete: gravitational convective instability, baroclinic instability, and symmetric instability (Haine and Marshall, 1998). Submesoscale dynamics are a very active field of research and an entire review paper would be necessary to present the results that have been obtained since the review of Thomas et al. (2008). The seasonality of submesoscale turbulence, with a higher intensity in winter when mixed layers are deep, is now well established from observations (e.g., Buckingham et al., 2016) and models (e.g., Couvelard et al., 2015).

\section{4 - Interactions with topography and continental slopes}

The ocean's bottom topography influences ocean eddies in a complex fashion, giving rise to dynamical phenomena that have strong implications for ocean forecasting. In rotating flows, bathymetry affects the entire water column up to the surface whenever the horizontal scale of the topography is larger than the Rossby radius. Topographic effects decay with height, with the Prandlt $e$-folding scale $\mathrm{h}_{\mathrm{e}}=f \mathrm{~L}_{\mathrm{t}} / N$, $\mathrm{L}_{\mathrm{t}}$ being the horizontal 
scale of the topography, $f$ being the Coriolis parameter, and $N$ being the buoyancy frequency. A few basic elements of flow-topography interaction at the mesoscale were reviewed by Rhines (1977) and recalled in section 3: topographic Rossby waves in the linear regime (whose e-folding scale away from the bottom is $h_{e}$ ), the effect of bottom roughness on the energy cascades in the nonlinear regime, and time-mean flow generation (the "Neptune" effect). Another well-known effect is the generation of eddies in the lee of seamounts, islands or coastal headlands. Bottom topography also influences baroclinic instability, the main generation mechanism for mesoscale eddies. Although many studies of baroclinic instability over a sloping bottom have been published since the 1970s, a thorough exploration of the two-layer QG flow on a beta-plane with slopes of varying orientations was only recently completed (Chen and Kamenkovich, 2013). Zonal slopes perpendicular to the zonal flow always destabilize it, while meridional slopes can have either a stabilizing or a destabilizing effect. Topography affects not only the growth rate of baroclinic instabilities, but also the orientation of the unstable modes and their vertical structure. The results of idealized and analytical models, such as Chen and Kamenkovich's, help us understand realistic situations such as the increased eddy activity that occurs as a zonal jet goes over a topographic ridge. The multiple effects of bathymetry on surface currents (instabilities and steering) have been demonstrated in Ocean General Circulation Models (OGCMs) used in operational applications (Hurlburt et al., 2008), emphasizing that an accurate representation of bottom topography is necessary for accurate ocean forecasts.

Models at resolutions of the order of $1 / 10^{\circ}$ reproduce reasonably well the surface eddy kinetic energy (EKE) observed by satellite altimetry (McClean et al., 2008, and references therein). This is true for a $1 / 12^{\circ}$ North Atlantic model developed by the Drakkar group in collaboration with Mercator-Ocean (Treguier et al., 2012). The Drakkar model also captures qualitatively the main energetic features of the EKE observed via the ARGO dataset (Ollitrault and Colin de Verdière, 2014) at $1000 \mathrm{~m}$ depth, closer to the bathymetry (see the comparison in Figure 5). Both observations and simulations highlight the westward increasing level of EKE. However the background level of EKE (outside the energetic regions) is lower than observed. This is in agreement with the analysis of Scott et al. (2010), who considered four eddying ocean circulation models: OCCAM (Ocean Circulation and Climate Advanced Modelling; based on the Bryan-Cox-Semtner model, see Webb, 2000), POP (Parallel Ocean Program, Maltrud and McClean, 2005), and two simulations of HYCOM (Hybrid Coordinate Ocean Model, Chassignet et al., 2009) with and without data assimilation. The models were compared with 5,000 current meter records. Scott et al. (2010) found that most models without data assimilation underestimated the EKE at depths. The considerable scatter in the point-wise comparison between models and current meters showed that models are not yet reliable to predict EKE at an arbitrary location in the deep ocean. Furthermore, the kinetic energy near the bathymetry was very dependent on the bottom friction coefficient used.

For numerical models, the most challenging bathymetric feature of the ocean is certainly the continental slope, a sharp transition between the deep ocean and the continental shelf that is associated with large topographic gradients. The continental slope supports fast vorticity waves called Coastal Trapped Waves (CTWs). CTWs have the same dynamics as topographic Rossby waves; these two types of linear solutions differ only by the choice of boundary conditions for the equations (Vangriesheim et al., 2005). 
CTWs propagate along the continental slope with the shallow water to the right in the Northern Hemisphere. Their structure depends on the Burger number $B u=\left(R_{d} / L\right)^{2}$, where $R_{d}$ is the Rossby radius and $L$ is the typical width of the slope. In the limit of high $B u$ (strong stratification), CTWs are identical to baroclinic Kelvin waves. At low $B u$, CTWs have a quasi-barotropic structure, similar to barotropic shelf waves. CTWs are observed on all of the continental slopes and are often related to wind forcing. Some examples would be the 15-day waves in the Gulf of Guinea (Vangriesheim et al., 2005); the 4-day waves in the eastern tropical Pacific (Flores Vidal et al, 2014), and current pulses in the eastern North Atlantic Bay of Biscay (Kersalé et al., 2016).

The asymmetry between the continental slopes at the eastern and western boundaries of ocean basins is striking. As explained by Henry Stommel (Stommel, 1948), strong western boundary currents are necessary to close the wind-forced gyres due to the asymmetry of the $\beta$ effect and Rossby waves dynamics. Western boundaries are thus closer to the main mesoscale energy source (baroclinic instability of strong mean flows), and the variability along the western continental slopes is forced by mesoscale structures and waves that propagate westward due to $\beta$. On the other hand, wind forcing is the major source of variability along the eastern continental slopes as recently documented by Le Boyer (2010). Two simulations using the $1 / 12^{\circ}$ model of Treguier et al. (2012) were performed to quantify the impact of wind stress fluctuations on the continental slopes: one experiment (BRD) with the full wind stress forcing and another (BST) where a low pass filter was applied to the wind stress to suppress variability at intraseasonal periods shorter than 90 days. Near the western boundary current, the circulation is dominated by mesoscale and submesoscale turbulence, and the EKE spectrum does not show any influence of the short period wind fluctuations (periods < 90 days) (Figure 6). Indeed, the spectra for both numerical simulations are very similar at both $200 \mathrm{~m}$ and $2000 \mathrm{~m}$ depth. Outside of these western boundary regions the influence of the short period winds increases as the total EKE decreases. Along the less energetic eastern boundary, most of the energy at periods < 90 days is generated by the wind. Figure 7 shows EKE spectra at $4^{\circ} \mathrm{N}$ in the Gulf of Guinea, at $200 \mathrm{~m}$ and $2000 \mathrm{~m}$. The difference between the two simulations is large, demonstrating the importance of wind forcing in the generation of variability along the eastern continental slope (Vangriesheim et al., 2005; Guiavarc'h et al, 2009). This is especially true at low latitudes, equatorward of $30^{\circ} \mathrm{N}$. The variability forced by the wind takes the shape of CTWs that propagate northward thousands of kilometers away from the equator. Figure 8 shows the space-time evolution of the along-shore surface current from $60^{\circ}$ north to $15^{\circ}$ south along the eastern continental slope in the BST simulation. The poleward propagation of the intraseasonal signal, away from the equator, is striking. Such propagation has been observed in tidal gauges on the eastern edge of the Pacific Ocean (Enfield and Allen, 1980) and in numerical simulations, but studies along the African coast are sparse and coherent propagation is documented only up to $15^{\circ} \mathrm{N}$ in observations (Polo et al., 2008). The model solution north of this latitude, displayed in Figure 8, has not yet been validated against in-situ or satellite data. These propagating waves found in numerical models are forced by a mix of anomalies resulting from local longshore and equatorial wind stress variability. Such characteristic dynamics of the eastern boundaries of ocean basins need to be taken into account when designing forecasting systems. While the accuracy of a five-day forecast along the eddy-rich western boundary depends mostly on an accurate initialization by existing mesoscale eddies, forecasts on the eastern boundary depend on the accuracy of the wind field. 
Moreover, basin-scale or global forecasts are required to represent the propagation of anomalies over a wide latitude range.

Eddying models are now used to explore the dynamics at higher frequencies, with simulations at very high resolution. Müller et al. (2015) used HYCOM to run $1 / 12^{\circ}$ and $1 / 25^{\circ}$ simulations forced by astronomical tides and t-hour atmospheric forcings. The high resolution simulation consistently shows a higher level of EKE in comparison with the $1 / 12^{\circ}$ simulation for both sub- and super-inertial frequencies, and the spectra at high frequency are closer to the theory of Garrett and Munk (1975). Such simulations, which attempt to resolve simultaneously the mesoscale, submesoscale, tidal motions, and internal waves, will make a considerable contribution to our understanding of ocean variability (Egbert, in press). With these new high resolution models, it will be possible to study flow-topography interactions, in both the mesoscale and the internal wave regimes, and to quantify the dissipation of mesoscale energy.

\section{5 - Numerical simulations of the ocean mesoscale variability}

This section outlines the development of the numerical models that have made possible the scientific advances reviewed in the previous sections. The first numerical simulation of oceanic mesoscales was performed using QG models. The earliest and most famous is probably W. Holland's (1978). QG models are computationally inexpensive because there is a single prognostic variable (the potential vorticity, from which the streamfunction is diagnosed) and there are no gravity waves to constrain the time step. A variety of QG models were developed in the 1970s and 1980s, with finite differences or spectral discretizations on the horizontal and either layers or modes on the vertical. Some of them were used for the first operational ocean forecasts (Robinson et al., 1984). However, because of the limitations of QG models (valid only when the Rossby number, aspect ratio, deviation from a background density field and variation of bottom topography are small enough), all forecasting systems now use the primitive equations. We provide a historical perspective on the applications of eddying primitive equation models in large domains (an ocean basin or the global ocean).

Given the limited computing resources available prior to the 1990s, general circulation models represented wind-driven gyres and the thermohaline circulation (e.g., Gill and Bryan, 1971) with low resolution grids (a few hundred kilometers). High resolution grids (a few tens of kilometers) were restricted to small domains, suitable for representing a single mesoscale eddy or an eddy field within an idealized small basin (e.g. Semtner and Mintz, 1977) or periodic and regional models (Miller et al., 1983, Haidvogel, 1983). This was clearly unsatisfactory because mesoscale turbulence interacts with the general circulation and contributes to shaping it (as discussed in the previous sections of this paper).

Holland et al. (1983) reviewed the eddying numerical models of idealized basins. The comparison between double gyre wind driven only and single gyre thermally and wind driven eddy kinetic energy in three benchmark simulations of the seventies (Holland, 1978, Robinson et al., 1977, Semtner and Mintz, 1977) showed already at that time that the source of kinetic energy for the mesoscale was both the westward and eastward flows of the ocean gyres. These currents undergo mixed baroclinic and barotropic 
instability. From their analysis, Holland et al. (1983) concluded that parameterizing the eddies in coarse resolution models was difficult and cumbersome, so eddies should be numerically resolved. As soon as the performance of computers made it possible, larger basin-scale and global eddying models were developed to capture the full range of eddymean flow interaction mechanisms.

The first eddying global model with realistic coastline and bathymetry (Semtner and Chervin, 1988) had a $1 / 2^{\circ}$ grid in longitude and latitude, and eddies could develop only in the tropics where the Rossby radius is large. The Fine Resolution Antarctic Model or FRAM (The FRAM group, 1991) had the same resolution of $1 / 2^{\circ}$ in longitude but a higher resolution in latitude, allowing eddy generation at mid-latitudes in the Southern Hemisphere. At the same time, in the framework of the World Ocean Circulation Experiment, a U.S.-led group designed the Community Model Experiment (CME), a North Atlantic model at $1 / 3^{\circ}$ (Bryan et al, 1995). All these models were run for about 20 years, allowing for the spin-up of wind-driven gyres and the development of mesoscale variability. Although these models would barely be called "eddy-permitting" by today's standards, they led to numerous model-data comparisons and analyses (more than 50 publications for FRAM and the CME).

Eddying models allowed, for the first time, the discovery of new ocean currents that were observed later on. The North Brazil undercurrent was described first in the CME model by Schott and Böning (1991) and subsequently mapped using ADCP measurements by Stramma et al. (1995). The North Queensland current was identified by Webb (2000) in the OCCAM project. Another example is the Zapiola Anticyclone, a very strong barotropic circulation (on the order of $100 \mathrm{~Sv}$ ) around a topographic feature (the "Zapiola drift") in the Argentine basin. This current was detected first in sigmacoordinate models as documented in de Miranda et al. (1999). Numerical models are also extremely useful in understanding individual current branches in the context of the basin-scale circulations. For example, although a southward flow had been observed previously on the Eastern flank of Reykjanes ridge, the East Reykjanes Ridge current was described for the first time as a part of the subpolar gyre circulation by Treguier et al. (2005), based on an intercomparison of eddying models.

Eddying models were much better suited than the earlier viscous models to study dynamical balances because the results were less dependent on arbitrary viscosity or diffusivity coefficients. Below are just a few of the results:

- The importance of baroclinic instability as a source of mesoscale variability has been confirmed.

- Deep currents have been described in more detail than was possible from observations alone (e.g., Böning and Schott, 1993).

- The computation of the energy cycle has demonstrated that the wind acts as source of available potential energy for large-scale ocean circulation (Treguier, 1992).

- The Mediterranean water overflow at Gibraltar has been shown to play a key role in the dynamics of the Azores current (Jia, 2000).

- The three-dimensional circulation underlying the Deacon Cell in the Southern Ocean has been explained (Doos and Webb, 1994), a major advance achieved by analyzing the FRAM model. 
However, many shortcomings of the models were also exposed including the incorrect location of the Gulf Stream separation, or the "short circuit" of the overturning circulation in the North Atlantic, due to excessive cross-isopycnal mixing in the western boundary current (the so-called "Veronis effect," Böning et al., 1995). Some of these problems, such as western boundary currents separation (see Chassignet and Marshall, 2008 for a review), have been overcome to a large extent by moving to higher resolutions, starting with the $1 / 12^{\circ}$ North Atlantic MICOM (Miami Isopycnic Coordinate Ocean Model) model (Paiva et al., 1999) and the $1 / 10^{\circ}$ North Atlantic POP model of Smith et al. (2000). These advances are well documented in a collection of papers edited by Hecht and Hasumi (2008). However, there is still a need for additional improvement in the numerical accuracy of the models and the representation of air-sea exchanges and flow-bathymetry interactions, as well as for increased horizontal and vertical grid spacing to resolve the Rossby radius over the whole globe (including high latitudes),

Below are just a few of the major issues for ongoing and future model development, regarding the simulation of the ocean mesoscale:

- By using more accurate numerical schemes, models have reduced the level of spurious mixing. There is a tight relationship between the momentum closure and spurious diapycnal mixing. The use of a higher order momentum advection scheme or a Smagorinsky viscosity helps reduce the noise in the velocity field, which limits numerical mixing of tracers (Ilicak et al., 2012). However, problems remain, such as the representation of dense water overflows.

- Moving to higher resolution improves the SST in models, but resolution is not enough to overcome all model biases. For example, SST biases in the upwelling regions are often due to inadequate atmospheric forcing.

- Pathways of major currents, such as the Gulf Stream and the North Atlantic Current, depend on feedbacks from the mesoscale variability through mechanisms such as Reynolds stress forcing of eastward jets or the Neptune effect. As a result, even in models with $1 / 10^{\circ}$ to $1 / 12^{\circ}$ grids, these pathways are still sensitive to parameterizations in the regions where the resolution is marginal relative to the Rossby radius (the subpolar gyres and the polar oceans) (Bryan et al., 2007; Chassignet and Marshall, 2008; Hecht et al., 2008). An example of unexplained spurious behavior in the model of Treguier et al. (2012) is shown in Figure 9.

- In simulations where the mesoscale is partially resolved, Large Eddy Simulation (LES) approaches with "scale aware" subgrid scale parameterizations should be developed (Fox-Kemper and Menemenlis, 2008). There is still no consensus on the "best" parameterizations for diffusivity and viscosity for eddy-resolving models.

- Major issues still exist regarding the representation of the surface layer of the ocean. Mesoscale eddies have an imprint of the surface mixed layer dynamics, but so have other processes such as surface waves, Langmuir circulations, mixed layer instabilities, near inertial waves, etc. Representing correctly all these processes in a coherent numerical framework is a daunting challenge for both climate applications and forecasting.

- With high-resolution modeling also comes the need for high-resolution topography. The most commonly used global bathymetric database is the Smith and Sandwell $(1997,2004) 1 / 2$ minute-resolution database, which is derived 
from a combination of satellite altimeter data and shipboard soundings and is continuously updated. Most, but not all, of the other available global bathymetric datasets, (i.e., the latest GEBCO bathymetry, ETOPO2, DBDB2, and so on) utilize the Smith and Sandwell database in the deep ocean. Differences can often be found in shallow water, where satellite altimetry is much less useful and where local high-quality datasets are often used. In areas not covered by such high resolution data, the true feature resolution of the Smith and Sandwell datasets is approximately 10-20 km. Goff and Arbic (2010) have created a synthetic dataset in which the topographic anomalies depend on local geophysical conditions such as seafloor spreading rate. The synthetic topography can be overlaid on the Smith and Sandwell datasets to create global bathymetries that have the correct statistical texture (roughness), even if the "bumps" are not deterministically correct.

\section{6 - Key challenges for data assimilation and forecast initialization at the mesoscale}

Data assimilation is essential for ocean prediction of mesoscale eddies because (a) they are due to nonlinear processes (i.e., flow instabilities) and thus are not a deterministic response to atmospheric forcing and (b) ocean models are imperfect, including limitations in numerical algorithms and in resolution. The quality of an ocean forecast will depend primarily on the quality of the initial conditions and the ability of the ocean numerical model to faithfully represent the ocean physics and dynamics.

Data assimilation, which combines observations with the numerical model, can provide the initial conditions, but cannot make up for a poorly performing numerical model. For high-resolution operational oceanography, the latter means that the numerical models need to accurately depict mean currents and mesoscale features, such as eddies and meandering fronts. As discussed in the previous sections, this implies that the grid spacing of the model must at least resolve the first Rossby radius of deformation, which can be as small as a few kilometers in the weakly-stratified polar regions or on the continental shelf. Current global operational forecasting systems have an equatorial resolution of $1 / 12^{\circ}(\sim 9 \mathrm{~km}$ near the equator, $\sim 7 \mathrm{~km}$ at mid-latitudes, and $\sim 3.5 \mathrm{~km}$ near the North Pole) (Chassignet et al., 2009; Lellouche et al., 2013, Metzger et al., 2014). The capacity to increase resolution to $1 / 25^{\circ}(\sim 3.5 \mathrm{~km}$ at mid-latitudes) is anticipated for 2017, including tidal forcing (J. Metzger, personal communication). As stated in section 4 , although the present generation of eddy-resolving global OGCMs at $\sim 1 / 10^{\circ}$ resolve the dominant eddy scale, the models significantly underestimate at this resolution the EKE in the abyssal ocean (i.e., depths greater than $3000 \mathrm{~m}$ ) (Scott et al., 2010). Increasing the model resolution to $1 / 25^{\circ}$ significantly increases the surface and the abyssal EKE to levels consistent with the observations, and clearly demonstrates the need for better representation of upper ocean EKE as a prerequisite for strong eddydriven abyssal circulation (Thoppil et al., 2011). The computational requirements for global ocean modeling at this resolution are, however, extreme and demand the latest in high-performance computing. For that reason, only two eddy-resolving global ocean models have been run for the past few years with data assimilation, as part of global forecast systems: HYCOM $1 / 12^{\circ}$ (Chassignet et al., 2009; Metzger at al., 2014), and 
NEMO $1 / 12^{\circ}$ (Lellouche et al., 2013). A recent review of the current status and future of global and regional ocean prediction systems was conducted by Tonani et al. (2015).

A number of issues, theoretical and technical, arise when a mesoscale numerical ocean model is used in conjunction with data assimilation techniques (Chassignet, 2011). Most of the information about the ocean surface's space-time variability is obtained remotely from instruments aboard satellites (i.e. SSH and SST), but these observations do not provide any information on the subsurface variability. A substantial source of subsurface data is provided by vertical profiles from expendable bathythermographs (XBTs), conductivity-temperature-depth (CTD) profilers, and profiling floats (e.g., Argo, which measure temperature and salinity in the upper $2000 \mathrm{~m}$ of the ocean). But even together, these datasets are insufficient to determine the state of the ocean completely and it is therefore necessary to use prior statistical knowledge based on past observations as well as our present understanding of ocean dynamics. By combining all of these observations through data assimilation into an ocean model, it is possible, in principle, to produce a dynamically consistent depiction of the ocean. But the biggest challenge for an eddy-resolving forecasting system is the assimilation of mesoscale eddies: satellite observations (SSH anomalies, SST) do form the bulk of the observations that can constrain the mesoscale fields, but they are limited in their coverage. Furthermore, in order to accurately assimilate the SSH anomalies determined from satellite altimeter data into the numerical model, it is necessary to know the oceanic mean SSH over the time period of the altimeter observations. In this, it is essential that the mean current systems and associated fronts be accurately represented in the oceanic mean SSH in terms of position, amplitude, and sharpness. This is challenging since the earth's geoid is not presently known with sufficient accuracy for this purpose, and coarse hydrographic climatologies $\left(\sim 0.5^{\circ}-1^{\circ}\right.$ horizontal resolution) cannot provide the spatial resolution necessary when assimilating SSH in an eddy-resolving model (horizontal grid spacing of $1 / 10^{\circ}$ or finer). Rio et al. (2014) recently derived a new mean dynamic topography using a combination of altimetry, gravimetry, and in situ data, where the small-scale structures are recovered from drifter data. This minimizes the systematic bias that can be introduced if the observed means of boundary currents and associated fronts is not sharply defined.

Conventional radar altimeters measure SSH profiles along satellite ground tracks. These profiles are then usually interpolated to form 2D maps using various mapping techniques (see Fu et al., 2010 and Morrow and Le Traon, 2012, for a review). However, given the distance between the satellites' ground tracks ( $\sim 80$ to $300 \mathrm{~km}$ ) and the repeat period ( $\sim 10$ to 35 days), the best $2 \mathrm{D}$ spatial resolution that can be achieved when combining data from several altimeters is on the order of $150 \mathrm{~km}$ in wavelength (Chelton et al, 2011). This means that most of the mesoscale features between 10 and $100 \mathrm{~km}$ are not captured in these 2D maps and that the ability to track a specific eddy will strongly depend on the choice of the interpolation technique (see Chassignet et al. (1992) for an early discussion of the issues and Ubelmann et al. (2015) for a recent summary). With the advent of the SWOT (Surface Water and Ocean Topography) satellite mission in 2020, it should be possible to resolving features at $15 \mathrm{~km}$ wavelength (Fu and Ubelmann, 2014). In order to retain information on the mesoscale, eddyresolving ocean forecasting systems do not assimilate these 2D maps: they assimilate the high resolution altimeter data along the ground tracks and let the ocean model physics act as a dynamical interpolator to adjust the modeled SSH fields between the 
ground tracks. Figure 10 provides an example of models' ability to represent the Gulf of Mexico Loop Current and associated eddies when compared to observed SeaWIFS data. The comparison is qualitative, but it clearly shows that resolution is of importance in properly representing the eddies and that SeaWiFS imagery is very effective in differentiating the ability of the systems to map the evolution of the Loop Current and associated warm and cold eddies, and in helping to diagnose specific strengths and weaknesses of the systems.

\section{7- Conclusions}

In this paper, we provide an historical perspective from the point of view of numerical modelers on how our understanding of ocean mesoscale dynamics has evolved over the past 40 years. First, we briefly review a few fundamental mechanisms such as baroclinic and barotropic instability, quasi-geostrophic turbulent cascades, and the effects of bottom topography. Then we introduce the theory of linear instability, which suggests a fundamental difficulty for mesoscale eddy forecasting; namely, that infinitesimal perturbations may have a strong influence on the solution. Due to space limitations, we did not discuss other nonlinear processes concepts such as deterministic chaos theory, localized instability, optimal perturbations, etc. (some are presented in Miller, in press). The impact of bathymetry is discussed extensively since it exerts a strong constraint on mesoscale dynamics. Eddies can be generated by currents flowing over topography, continental shelves support coastal-trapped waves, topographic Rossby waves and Kelvin waves, and even the surface layers of the ocean are influenced by bottom topography. Bathymetry also controls energy cascades and modifies the stability properties of the flow. Thus an accurate representation of topography as well as flowtopography interaction is essential for good forecasts. This will become even more important when ocean forecasting systems begin to include an explicit representation of the tides and their interactions with topography.

The processes we have chosen to present here mainly concern the relationship between the mesoscale and large-scale ocean circulation: how eddies draw energy from the large scale flow and how they contribute to shape it through rectification effects. We have not covered in detail the other end of the spectrum: how is mesoscale energy dissipated? How do eddies interact with internal gravity waves and tides? Many research activities are now devoted to addressing these questions using observations, numerical simulations, and theory. Indeed, we must expand our understanding of submesoscale dynamics and dissipation in order to build more robust models of mesoscale features. It is very likely that forecasting the submesoscales (typically, $1 \mathrm{~km}$ wide filaments) will be possible in the near future in some regions with the increased availability of higher resolution satellite data and observations.

The last two sections of this paper discuss current challenges for numerical models and for data assimilation at the mesoscale. These challenges are also relevant for modeling and forecasting basin scale circulations because the most energetic flows in ocean basins are western boundary currents and fronts whose width is on the order of the Rossby radius. We did not address theoretical and numerical developments that are not being used for ocean forecasting, such as contour dynamics and "contour surgery" models. However, these are powerful tools to understand the behavior of coherent eddies 
(Dritschel, 1988). The "next frontier" regarding mesoscale simulations and forecasts is likely the systematic use of ensemble simulations, as currently the case for weather forecasting and climate scenarios, to address the chaotic nature of the mesoscale and its impact on the global ocean. A new effort is underway to build an ensemble of 50 global eddying simulations (Penduff et al., 2014). These ground-breaking simulations will allow us to map regions of the world ocean where the mesoscale is most likely to contribute to the low frequency variability of the ocean, and therefore affect long-term (seasonal and decadal) climate forecasts.

Given the size of the world ocean when compared to the Rossby radius of deformation, this paper is by no means an all-inclusive description of the incredible variety of mesoscale eddy dynamics. But, it illustrates the progress made to date and the potential for significant advances to be made in the near future, particularly in the area of submesoscale dynamics.

\section{Acknowledgements}

A.M. Treguier and A. Le Boyer thank Guillaume Roullet for fruitful discussions about mesoscale dynamics on the continental slope, and Noe Lahaye for providing Figure $4 \mathrm{~b}$. A.M. Treguier is supported by CNRS, and received funding from ANR Project COMODO (ANR-11-MONU-005). The Drakkar group is supported by CNRS, Ifremer, and MercatorOcean. The Drakkar $1 / 12^{\circ}$ simulations used in this paper have been performed on the GENCI supercomputing centers in France. E.P. Chassignet acknowledges support from the project "Earth System Prediction Capability" sponsored by the Office of Naval Research.

\section{References}

Adcroft, A., R. Hallberg, J. P. Dunne, B. L. Samuels, J. A. Galt, C. H. Barker, and D. Payton, 2010. Simulations of underwater plumes of dissolved oil in the Gulf of Mexico, Geophys. Res. Lett., 37, L18605, doi:10.1029/2010GL044689.

Böning, C. W., and F. A. Schott, 1993. Deep currents and the Eastward salinity tongue in the Equatorial Atlantic: Results from an eddy-resolving, primitive equation model. J. Geophys. Res., 98, 6991-6999.

Böning, C. W., R. Holland, F. O. Bryan, G. Danabasoglu, and J.C. McWilliams, 1995. An overlooked problem in model simulations of the thermohaline circulation and Heat transport in the Atlantic ocean. J. Climate, 8, 515-523.

Bretherton, F.P. and M.J. Karweit, 1975. Mid-ocean mesoscale modelling. In: Numerical models of ocean circulation, Ocean affairs board of the National Research Council, 237249.

Bryan, F.O., C. W. Boening, and W.R. Holland, 1995. On the circulation in a highresolution model of the North Atlantic, J. Phys. Oceanogr., 25, 289-305. 
Bryan, F. O., M. W. Hecht, and R. D. Smith, 2007. Resolution, convergence and sensitivity studies with North Atlantic circulation models. Part I: The western boundary current system. Ocean Modelling, 16, 141-159.

Buckingham, C. E., A. C. Naveira Garabato, A. F. Thompson, L. Brannigan, A. Lazar, D. P. Marshall, A. J. George Nurser, G. Damerell, K. J. Heywood, and S. E. Belcher, 2016. Seasonality of submesoscale flows in the ocean surface boundary layer, Geophys. Res. Lett., 43, 2118-2126, doi:10.1002/2016GL068009.

Carton, X., 2010. Oceanic Vortices. In Fronts, Waves and Vortices. Lect. Notes in Physics, 805, Springer-Verlag, 61-108.

Charney, J.G., 1947. The dynamics of long waves in a baroclinic westerly current. J. Meteor., 4, 135-162.

Charney, J.G., R. Fjortoft, and J. Von Neumann, 1950. Numerical integration of the barotropic vorticity equation. Tellus, 2, 237-254.

Charney, J.G., 1971. Geostrophic Turbulence. J. Atmos. Sci., 28, 1087-1095.

Chassignet, E.P., W.R. Holland, and A. Capotondi, 1992. Impact of the altimeter orbit on the reproduction of oceanic rings: Application to a regional model of the Gulf Stream. Oceanologica Acta, 15, 479-490.

Chassignet, E.P., H.E. Hurlburt, O.M. Smedstad, C.N. Barron, D.S. Ko, R.C. Rhodes, J.F. Shriver, A.J. Wallcraft, and R.A. Arnone, 2005. Assessment of data assimilative ocean models in the Gulf of Mexico using ocean color. In "Circulation in the Gulf of Mexico: Observations and models", W. Sturges and A. Lugo-Fernandez, Eds., AGU Monograph Series, 161, 87-100.

Chassignet, E.P., and D.P. Marshall, 2008. Gulf Stream separation in numerical ocean models. In "Eddy-Resolving Ocean Modeling", M. Hecht and H. Hasumi, Eds., AGU Monograph Series, 39-62.

Chassignet, E.P., H.E. Hurlburt, E.J. Metzger, O.M. Smedstad, J. Cummings, G.R. Halliwell, R. Bleck, R. Baraille, A.J. Wallcraft, C. Lozano, H.L. Tolman, A. Srinivasan, S. Hankin, P. Cornillon, R. Weisberg, A. Barth, R. He, F. Werner, and J. Wilkin, 2009. U.S. GODAE: Global Ocean Prediction with the HYbrid Coordinate Ocean Model (HYCOM). Oceanography, 22(2), 64-75.

Chassignet, E.P., 2011. Isopycnic and hybrid ocean modeling in the context of GODAE. In "Operational Oceanography in the 21st Century", A. Schiller and G. Brassington, Eds., Springer, 263-294.

Chelton, D.B., R. A. deSzoeke, M. G. Schlax, K. El Naggar and N. Siwertz, 1998. Geophysical variability of the first baroclinic Rossby radius of deformation. J. Phys. Oceanogr., 28, 433- 460. 
Chelton, D.B., M. G. Schlax, R.M. Samelson, 2011. Global observations of nonlinear mesoscale eddies. Prog. Oceanogr., doi:10.1016/ j.pocean.2011.01.002

Chen, C. and I Kamenkovich, 2013. Effects of Topography on Baroclinic Instability. J. Phys. Oceanogr., 43, 790-804.

Couvelard, X., F. Dumas, V. Garnier, A. Ponte, C. Talandier, A.M. Treguier, 2015. Mixed Layer formation and restratification in presence of mesoscale and submesoscale turbulence. Ocean Modelling, 96, 243-253.

Cushman-Roisin, B., E.P. Chassignet, and B. Tang, 1990. Westward motion of mesoscale eddies. J. Phys. Oceanogr., 20, 758-768.

de Miranda, A. P., B. Barnier, W.K. Dewar, 1999. On the dynamics of the Zapiola anticyclone. J. Geophys. Res., 104, 21137-21150.

Doos, K., and D. J. Webb, 1994. The Deacon cell and the other meridional cells of the southern ocean. J. Phys. Oceanogr., 24, 429-442.

Dritschel, D. G., 1988. Contour surgery: a topological reconnection scheme for extended integrations using contour dynamics. J. comput. Phys., 77, 240-266.

Eady, E.T., 1949. Long waves and cyclone waves. Tellus, 1, 33-52.

Early, J.J., R. M. Samelson, and Dudley B. Chelton, 2011. The evolution and propagation of quasigeostrophic ocean eddies. J. Phys. Oceanogr., 41, 1535-1555.

doi: http://dx.doi.org/10.1175/2011JP04601.1

Egbert, G., 2017: Tidal predictions (barotropic and internal), Internal wave modeling and predictions, topographic effects, mixing and dissipation. J. Mar. Res., (STATUS?)

Enfield, D. B., and J. S. Allen, 1980. On the structure and dynamics of monthly mean sea level anomalies along the Pacific coast of North and South America. J. Phys. Oceanogr., 10, 557-578, doi:10.1175/1520-0485(1980)010,0557:OTSAD0.2.0.C0;2.

Flores-Vidal, X., R Durazo, L Zavala-Sansón, P Flament, C Chavanne, F.J. Ocampo-Torres, C. Reyes Hernandez, 2014. Evidence of inertially generated coastal - trapped waves in the eastern tropical Pacific. Journal of Geophysical Research: Oceans 119 (5), 31213133.

Fox-Kemper, B., and D. Menemenlis, 2008. Can large eddy simulation techniques improve mesoscale-rich ocean models? In M. Hecht and H. Hasumi, editors, Ocean Modeling in an Eddying Regime, volume 177, pages 319-338. AGU Geophysical Monograph Series.

The FRAM group, 1991. An eddy-resolving model of the southern ocean. EOS, Trans. Amer. Geophys. Union, 72, pages 169, 174-175. 
$\mathrm{Fu}$, L.-L., and C. Ubelmann, 2014. On the transition from profile altimeter to swath altimeter for observing global ocean surface topography. J. Atmos. Oceanic Technol., 31 , 560-568, doi:10.1175/JTECH-D-13-00109.

Fu, L.-L., D. B. Chelton, P.-Y. Le Traon, and R. Morrow, 2010. Eddy dynamics from satellite altimetry. Oceanography, 23, 14-25, doi:10.5670/oceanog.2010.02

Garrett, C. and W. Munk, 1975. space-time scales of internal waves: a progress report. J. Geophys. Res., 80, 291-297.

Gill, A.E. and K. Bryan, 1971. Effects of geometry on the circulation of a threedimensional southern hemisphere ocean model. Deep Sea Res., 18, 685-721.

Goff, J.A., and B.K. Arbic, 2010. Global prediction of abyssal hill roughness statistics for use in ocean models from digital maps of paleo-spreading rate, paleoridge orientation, and sediment thickness. Ocean Modelling 32:36-43. doi:10.1016/j.ocemod.2009.10.001

Guiavarc'h, C., A.M. Treguier and A. Vangriesheim, 2009. Deep currents in the Gulf of Guinea: along slope propagation of intraseasonal waves. Ocean Science, 5, 141-153.

Haidvogel, D.B., 1983. Periodic and regional models. In: Eddies in Marine Science, 609 pp., Springer-Verlag, New York/Heidelberg, Robinson, A.R. (Editor)

Haine, TWN, and J Marshall, 1998. Gravitational, symmetric, and baroclinic instability of the ocean mixed layer. Journal of Physical Oceanography 28 (4), 634-658.

Hecht, M.W., Hasumi, H. (Eds.), 2008. Ocean Modeling in an Eddying Regime. AGU Monograph Series 177. AGU.

Hogg, N.G., and W.B. Owens, 1999. Direct measurement of the deep circulation within the Brazil Basin. Deep Sea Res., 46, 335-353.

Holland, W.R., 1978. The Role of Mesoscale eddies in the General Circulation of the Ocean- Numerical experiments using a wind-driven quasi-geostrophic model. J. Phys. Oceanogr., 8, 363-392.

Holland, W. R., D. E. Harrison, and A. J. Semtner, Jr., 1983. Eddy-Resolving Numerical models of Large-Scale Ocean Circulation. Eddies in Marine Science, Chapter 17. Ed. A. R. Robinson, Springer Verlag, 379-403.

Holloway, G., 1992. Representing topographic form stress for large-scale ocean models. J. Phys. Oceanogr., 22, 1033-1046.

Huppert, H.E., and K. Bryan, 1976. Topographically generated eddies. Deep Sea Res., 23, 655-679.

Hurlburt, H.E., E.J. Metzger, P.J. Hogan, C.E. Tilburg, J.F. Shriver, 2008. Steering of upper ocean currents and fronts by the topographically constrained abyssal circulation. Dynamics of Atmospheres and Oceans, 45, 102-134. 
Ilıcak, M., Adcroft, A., Griffies, S. M., Hallberg , R., 2012. Spurious dianeutral mixing and the role of momentum closure, Ocean Modelling , 45-46, 37-58.

Jia, Y.L., 2000. On the formation of an Azores Current due to Mediterranean Overflow in a modeling study of the North Atlantic. J. Phys. Oceanogr., 30, 2342-2358,

Kersale, M., Marié L., Le Cann B., Serpette A., Lathuiliere C., Le Boyer A., Rubio A., Lazure P., 2016. Poleward along-shore current pulses on the inner shelf of the Bay of Biscay. Estuarine, Coastal and Shelf Science, 179, 155-171.

http://doi.org/10.1016/j.ecss.2015.11.018

Killworth, P.D., 1980. Barotropic and baroclinic instability in rotating stratified fluids. Dyn. Atmos. Oceans, 4: 143-184.

Kuo, H.L., 1949. Dynamic instability of two-dimensional non-divergent flow in a barotropic atmosphere. J. Meteorol., 6, 105-122.

Lahaye, N., and V Zeitlin, 2012. Decaying vortex and wave turbulence in rotating shallow water model, as follows form high resolution direct simulations. Phys. Fluids, 24(11):115106:1-13.

Le Boyer, 2010. Variabilité intra-saisonnière des courants de pente continentale forcés par la turbulence méso-échelle. Ph. D. thesis, university of Brest.

Lellouche, J.-M., Le Galloudec, O., Drévillon, M., Régnier, C., Greiner, E., Garric, G., Ferry, N., Desportes, C., Testut, C.-E., Bricaud, C., Bourdallé-Badie, R., Tranchant, B., Benkiran, M., Drillet, Y., Daudin, A., and De Nicola, C., 2013. Evaluation of global monitoring and forecasting systems at Mercator Océan, Ocean Sci., 9, 57-81, doi:10.5194/os-9-57-2013.

Mahadevan, A., and A. Tandon, 2006. An analysis of mechanisms for submesoscale vertical motion at ocean fronts. Ocean Modelling, 14, 241-256.

Maltrud, M.E., and J.L. McClean, 2005. An eddy resolving global 1/10 degree ocean simulation. Ocean Modell., 8, 31-54.

Maximenko, N.A., B. Bang and H Sasaki, 2005. Observational evidence of alternating zonal jets in the world ocean. Geophys. Res. Let., 32, L12607.

McClean, J., Jayne, S., Maltrud, M. and Ivanova, D., 2008. The fidelity of ocean models with explicit eddies, in Ocean Modeling in an Eddying Regime (eds M. W. Hecht and H. Hasumi), American Geophysical Union, Washington, D. C. doi: 10.1029/177GM11

McWilliams, J.C., Flierl, G.R., 1979. On the evolution of isolated, non-linear vortices, J. Phys. Oceanogr., 9, 1155-1182.

McWilliams, J.C., W.B. Owens, \& B.L. Hua, 1986. An objective analysis of the POLYMODE Local Dynamics Experiment. I. General formalism and statistical model parameters. J. Phys. Ocean. 16, 483-504. 
McWilliams, J. C. 1989. Statistical properties of decaying geostrophic turbulence. J. Fluid Mech. 198, 361-385.

Metzger, E.J., O.M. Smedstad, P.G. Thoppil, H.E. Hurlburt, J.A. Cummings, A.J. Wallcraft, L. Zamudio, D.S. Franklin, P.G. Posey, M.W. Phelps, P.J. Hogan, F.L. Bub, and C.J. DeHaan. 2014. US Navy operational global ocean and Arctic ice prediction systems. Oceanography 27(3):32-43, http://dx.doi.org/10.5670/oceanog.2014.66.

Miller, R.N., A.R. Robinson and D.B. Haidvogel, 1983. A Baroclinic Quasigeostrophic Open Ocean Model. Journal of Computational Physics, 50(1), 38-70.

Miller, R..N, 2017. Ocean Predictability (include predictability theory, conceptual/mathematical definitions, simple nonlinear dynamical systems, stability, real systems, atmospheric vs. oceanic predictability, predictability at different scales, could touch briefly on predictive capability). J. Mar. Res. Final title and STATUS?

MODE Group, 1979. The Mid Ocean Dynamics Experiment. Deep-Sea Research, 25, 859910.

Morrow, R., and P.Y. Le Traon, 2012. Recent advances in observing mesoscale ocean dynamics with satellite altimetry. Advances in space research, 50, 1062-1076.

Müller, M., B. K. Arbic, J. G. Richman, J. F. Shriver, E. L. Kunze, R. B. Scott, A. J. Wallcraft, and L. Zamudio (2015). Toward an internal gravity wave spectrum in global ocean models, Geophys. Res. Lett., 42, 3474-3481, doi:10.1002/2015GL063365.

Ollitrault M., and A. Colin de Verdière, 2014. The Ocean General Circulation near 1000-m Depth. J. Phys. Oceanogr., 44, 384-409. doi: http://dx.doi.org/10.1175/JPO-D-13-030.1

Olson, D. B., 1991. Rings in the ocean, Annu. Rev. Earth Planet. Sci., 19, 283-311.

Paiva, A.M., J.T. Hargrove, E.P. Chassignet, and R. Bleck, 1999. Turbulent behavior of a fine mesh (1/12 degree) numerical simulation of the North Atlantic. J. Mar. Sys., 21, 307320.

Pedlosky, J., 1987. Geophysical Fluid Dynamics. 2d ed. Springer-Verlag, 710 pp

Penduff, T., M. Juza, B. Barnier, J. Zika, W.K. Dewar, A.M. Treguier, J.M. Molines, N. Audiffren, 2011. Sea-level expression of intrinsic and forced ocean variabilities at interannual time scales. Journal of Climate, 24, 5652-5670. doi. 10.1175/JCLI-D-1100077.1

Penduff, T., B. Barnier, L. Terray, L. Bessières, G. Serazin, S. Gregorio, J.M. Brankart, M.P. Moine, J.M. Molines, and P Brasseur, 2014: Ensembles of eddying ocean simulations for climate. Clivar exchanges, 65, vol 19, 26-29. 
Polo, I., A. Lazar, B. Rodriguez-Fonseca, and S. Arnault, 2008. Oceanic Kelvin waves and tropical Atlantic intraseasonal variability: 1. Kelvin wave characterization, J. Geophys. Res., 113, C07009, doi:10.1029/2007JC004495.

Rhines, P. B., 1977. The dynamics of unsteady currents. In The Sea, 6, 189-318. E. A. Goldberg, I. N. McCane, J. J. O Brien, and J. H. Steele, Eds., J. Wiley and Sons.

Rio, M.-H., S. Mulet, and N. Picot, 2014. Beyond GOCE for the ocean circulation estimate: Synergetic use of altimetry, gravimetry, and in situ data provides new insight into geostrophic and Ekman currents, Geophys. Res. Lett., 41, 8918-8925, doi:10.1002/2014GL061773.

Robinson, A.R., D.E. Harrison, Y Mintz, A.J. Semtner, 1977. Eddies and the general circulation of an idealized oceanic gyre: a wind and thermally driven primitive equation numerical experiment. J. Phys. Oceanogr., 7:182-207.

Robinson, A.R., 1983. Eddies in Marine Science (Edited by A.R. Robinson), 609 pp., Springer-Verlag, New York/Heidelberg.

Robinson, A.R., J.A. Carton, C.N.K. Mooers, L.J. Walstad, E.F. Carter, M.M. Rienecker, J.A. Smith, and W.G. Leslie, 1984. A Real-Time Dynamical Forecast of Ocean Synoptic/Mesoscale Eddies. Nature, 309(5971), 781-783.

Roullet, G., and P. Klein, 2010. Cyclone-anticyclone asymmetry in geophysical turbulence. Phys. Rev. Lett., 104, 218501. DOI: 10.1103/PhysRevLett.104.218501

Schott, F. and C. W. Böning, 1991. The WOCE Model in the western Equatorial Atlantic: Upper layer circulation. J. Geophys. Res., 96, 6993-7004.

Scott, R. B., and F Wang, 2005. Direct evidence of an oceanic inverse kinetic energy cascade from saltellite altimetry. J. Phys. Oceanogr., 35, 1650-1666.

Scott, R. B., B. K. Arbic, E. P. Chassignet, A. C. Coward, M. Maltrud, W. J. Merryfield, A. Srinivasan, and A. Varghese, 2010. Total kinetic energy in four global eddying ocean circulation models and over 5000 current meter records, Ocean Modell., 32(3-4), 157169, doi:10.1016/j.ocemod. 2010.01.005.

Semtner, Jr, and Chervin R.M., 1988: A simulation of the Global Ocean circulation with resolved eddies. J. Geophys. Res., 93, 15502-15522.

Semtner, A. J., and Y. Mintz, 1977. Numerical simulation of the Gulf Stream and midocean eddies. J. Phys. Oceanogr., 208-230.

Sérazin, G., T. Penduff, S. Grégorio, B. Barnier, J.-M. Molines, and L. Terray, 2015 . Intrinsic variability of sea-level from global $1 / 12^{\circ}$ ocean simulations: spatio-temporal scales. J. Climate, 28, 4279-4292. doi: http://dx.doi.org/10.1175/JCLI-D-14-00554.1 
Smith, W.H.F., and Sandwell D.T., 1997. Global seafloor topography from satellite altimetry and ship depth soundings: evidence for stochastic reheating of the oceanic lithosphere. Science 277:1956-1962

Smith, W.H.F., and Sandwell D.T., 2004. Conventional bathymetry, bathymetry from space, and geodetic altimetry. Oceanography 17:8-23

Smith, R.D., M. E. Maltrud, F. O. Bryan, and M. W. Hecht, 2000. Numerical simulation of the North Atlantic Ocean at $1 / 10^{\circ}$. J. Phys. Oceanogr., 30, 1532-1561.

Smith, K. S. and G. K. Vallis. 2002. Scales and equilibration of mid-ocean eddies: Forceddissipative flow. J. Phys. Oceanogr., 32, 1699-1721.

Smith, K.S., 2007. The geography of linear baroclinic instability in Earth's oceans. J. Mar. Res., 65, 655-683.

Stommel, H., 1948. The westward intensification of wind-driven ocean currents. EOS transactions, AGU, vol 29, 202-206.

Stramma, L., J. Fisher, and J. Reppin, 1995., The North Brazil Undercurrent, Deep Sea Res., 42, 773-795.

Thomas, L. A. Tandon and A. Mahadevan, 2008. Submesoscale ocean processes and dynamics. In Ocean Modeling in an Eddying Regime, Eds. M. Hecht and H. Hasumi, Geophysical Monograph 177, American Geophysical Union, Washington D.C., p 17-38.

Thoppil, P.G., J.G. Richman and P.J. Hogan, 2011. Energetics of a global ocean circulation model compared to observations. Geophys. Res. Lett., 38, L15607, doi:10.1029/2011GL048347.

Tonani, M., M. Balmaseda, L. Bertino, E. Blockley, G. Brassington, F. Davidson, Y. Drillet, P. Hogan, T. Kuragano, T. Lee, A. Mehra, F. Paranathara, C.A.S. Tanajura, and H. Wang, 2015. Status and future of global and regional ocean prediction systems. Journal of Operational Oceanography, 8, Iss. sup2, 201-220. Doi:10.1080/1755876X.2015.1049892.

Treguier, A.M., N. G. Hogg, M. Maltrud, K. Speer, V. Thierry, 2003: Origin of deep zonal flows in the Brazil Basin. J. Phys. Oceanogr., 33,580-599.

Treguier, A.M. and B.L. Hua, 1987. Oceanic quasi-geostrophic turbulence forced by stochastic wind fluctuations, J. Phys. Oceanogr., 17, 397-411.

Treguier, A.M., 1992. Kinetic energy analysis of an eddy resolving, primitive equation North Atlantic model. J. Geophys. Res., 97, 687-701.

Treguier, A.M., S. Theetten, E Chassignet, T. Penduff, R Smith L Talley C. Böning, J.O. Beismann, 2005. The North Atlantic subpolar gyre in four high resolution models. J. Phys. Oceanogr., 35, 757-774 
Treguier, A. M., J. Deshayes, C. Lique, R. Dussin, and J. M. Molines, 2012. Eddy contributions to the meridional transport of salt in the North Atlantic, J. Geophys. Res., 117, C05010, doi:10.1029/2012JC007927.

Treguier, A.M., J. Deshayes, J. Le Sommer, C. Lique, G. Madec, T. Penduff, J.-M. Molines, B. Barnier, R. Bourdalle-Badie, and C. Talandier, 2014. Meridional transport of salt in the global ocean from an eddy-resolving model. Ocean Sci., 10, 243-255, 2014

Ubelmann, C., P. Klein, and L.-L. Fu, 2015. Dynamic Interpolation of Sea Surface Height and Potential Applications for Future High-Resolution Altimetry Mapping, Journal of Atmospheric and Oceanic Technology, 32:1, 177-184

Vangriesheim A., A.M. Treguier, and G. Andre, 2005. Biweekly current oscillations on the continental slope of the Gulf of Guinea. Deep Sea Res., 52,11, 2168-2183.

Webb, D., 2000. Evidence for shallow zonal jets in the South Equatorial Current region of the southwest Pacific. Journal of Physical Oceanography, 30, 706 - 720. 


\section{FIGURE CAPTIONS}

Figure 1 : Snapshot of the surface velocity amplitude $(\mathrm{cm} / \mathrm{s})$ in the $1 / 12^{\circ}$ global Drakkar model (december 1992 hindcast). A model description is found in Treguier et al. (2014).

Figure 2: Time evolution of a weakly baroclinically unstable jet in a periodic channel in a two layers QG model. The initial condition is a zonal flow in the top layer and a low amplitude random streamfunction in the lower layer. Initially, the lower layer streamfunction, being much smaller than the upper layer, is displayed by black contours (with a factor of ten contour interval compared with the upper layer). After a year, the perturbation grows and the lower layer flow is dominated by the linearly most unstable wave, with a scale larger than the Rossby radius (the Rossby radius wavelength is $1 / 5$ th the channel length). This is an illustration of the scale selection process which explains the spatial scale of the most energetic structures in the ocean. At longer times, the most unstable wave reaches a large amplitude and has an imprint in both layers. Finally, the finite amplitude perturbation cascades towards larger spatial scales horizontally and becomes quasi-barotropic. Negative values are indicated by the blue color or by dashed contours. Contour interval is $2000 \mathrm{~m}^{2} / \mathrm{s}$, excepted for the lower layer at day 6 and day 315 (contour interval $200 \mathrm{~m}^{2} / \mathrm{s}$ ).

Figure 3: Simulations of barotropic free decaying turbulence (Rhines, 1977). The pseudo-spectral QG model has an equivalent resolution of 64x64 points. It is initialized with a random field (left). After 5 months, the flow evolution of the streamfunction on a f-plane shows the cascade of energy towards large scales, limited only by the size of the domain. On a beta-plane (bottom), the cascade is halted at the Rhines scale and the flow becomes anisotropic with a predominance of zonal currents. Contours for the nondimensional streamfunction are 0.11 at $\mathrm{T}=0$ and 0.16 at $\mathrm{T}=5$. Negative contours are dashed.

Figure 4 : Vorticity field in free decaying turbulence on a f-plane. a) low resolution barotropic model of Rhines (1977), 64×64 grid points; the vorticity after 5 months is elongated into filaments. b) high resolution simulation of Lahaye and Zeitlin (2012), with $512 \times 512$ points and a domain size of 8 Rossby radius wavelengths. The color scale is in units of vorticity normalized by $f$. Coherent structures appear in the high resolution simulation but not a low resolution.

Figure 5: Logarithm of the eddy kinetic energy $\left(\mathrm{m}^{2} \mathrm{~s}^{-2}\right)$ at $1000 \mathrm{~m}$ depth. A): from ARGO floats (Ollitrault and Colin de Verdière, 2014); b) from the North Atlantic $1 / 12^{\circ}$ model. White pixels represent either shallow regions (depth $<1000 \mathrm{~m}$ ) or mission data in the case of ARGO.

Figure 6: KE distribution at $200 \mathrm{~m}$ depth in the Gulf Stream area from the North Atlantic $1 / 12^{\circ}$ model (a). The frequency spectra (b) represent the EKE distribution on the $35^{\circ} \mathrm{N}$ section from the North Atlantic $1 / 12^{\circ}$ model forced by realistic wind forcing (BRD simulation, red lines) and low frequency wind forcing (BST simulation, black lines) at $200 \mathrm{~m}$ and $2000 \mathrm{~m}$ depth (solid and dashed lines, respectively) 
Figure 7: KE distribution at $200 \mathrm{~m}$ depth in the gulf of Guinea area from the North Atlantic $1 / 12^{\circ}$ model (a). The frequency spectra (b) represent the EKE distribution on the $4^{\circ} \mathrm{N}$ section from the North Atlantic $1 / 12^{\circ}$ model forced by realistic wind forcing (BRD simulation, red lines) and low frequency wind forcing (BST simulation, black lines) at $200 \mathrm{~m}$ and $2000 \mathrm{~m}$ depth (solid and dashed lines, respectively)

Figure 8: a) Time evolution of the along-shore surface velocity along the continental slope of the Eastern Atlantic (following the $500 \mathrm{~m}$ isobath) from the North Atlantic $1 / 12^{\circ}$ model, for year 1990. The colorbar is in $\mathrm{m} \mathrm{s}^{-1}$. b) Distance following the continental slope in $\mathrm{km}$ from the northern point of the domain. The velocity is high-pass filtered with a cutoff period of 90 days.

Figure 9: Rms sea surface height anomaly (SSHA, $\mathrm{cm}$ ) from satellite observations (top) and the $1 / 12^{\circ}$ North Atlantic model of Treguier et al (2012). Although the model reproduces well the Gulf Stream path and the North West corner, a spurious branch of the North Atlantic current appears in the subpolar gyre after 1995. This branch entering the Irminger Sea is warm, stratified and baroclinially unstable, and shows up as a filament of high SSHA around $37^{\circ} \mathrm{W}, 57^{\circ} \mathrm{N}$ in the model. This spurious behavior has been found in a few regional and global simulations at $1 / 12^{\circ}$ using the NEMO model; it does not appear at lower resolution $\left(1 / 4^{\circ}\right)$. This demonstrates that large scale circulations in numerical models depends on the representation of mesoscale eddies and flowtopography interactions, which are not robust even at $1 / 12^{\circ}$.

Figure 10: SSH from four ocean data assimilative systems on 26 July 2003 (contour interval of $10 \mathrm{~cm}$ and normalized over the displayed area), overlying ocean color imagery from SeaWiFS (natural log of the concentration in $\mathrm{mg} \mathrm{m}^{-3}$ ). The model land-sea boundary is defined by the black contour line. This figure illustrates the models' ability to represent the Gulf of Mexico Loop Current and associated eddies when compared to the observed SeaWIFS data. The comparison is qualitative, but it clearly shows that resolution is of importance in properly representing the eddies and that SeaWiFS imagery is very effective in differentiating the ability of the systems to map the evolution of the Loop Current and associated warm and cold eddies, and in helping to diagnose specific strengths and weaknesses of the systems.

(From Chassignet et al., 2005). 

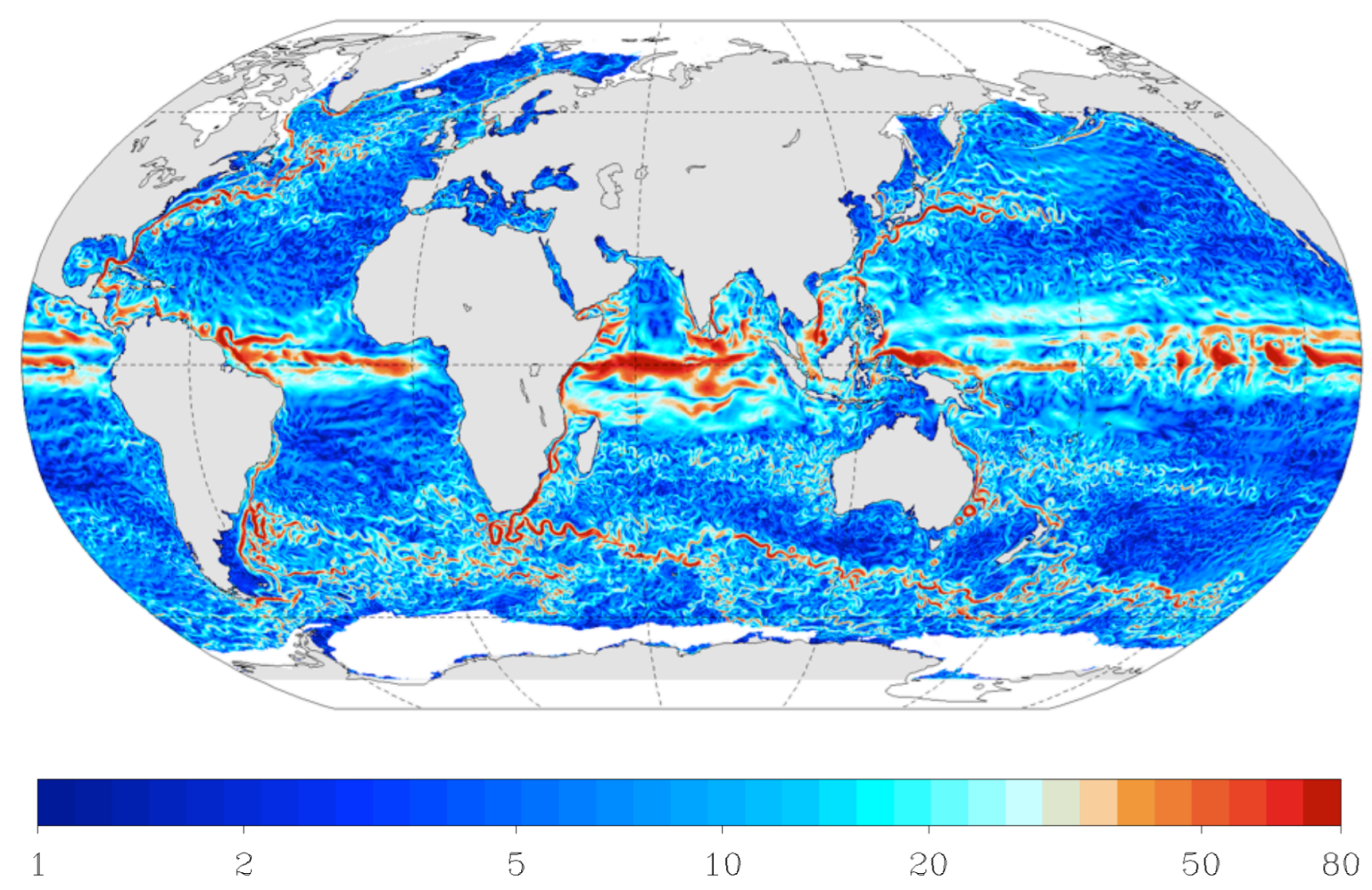

Figure 1 : Snapshot of the surface velocity amplitude $(\mathrm{cm} / \mathrm{s})$ in the $1 / 12^{\circ}$ global Drakkar model (december 1992 hindcast). A model description is found in Treguier et al. (2014). 
Streamfunction layer 1
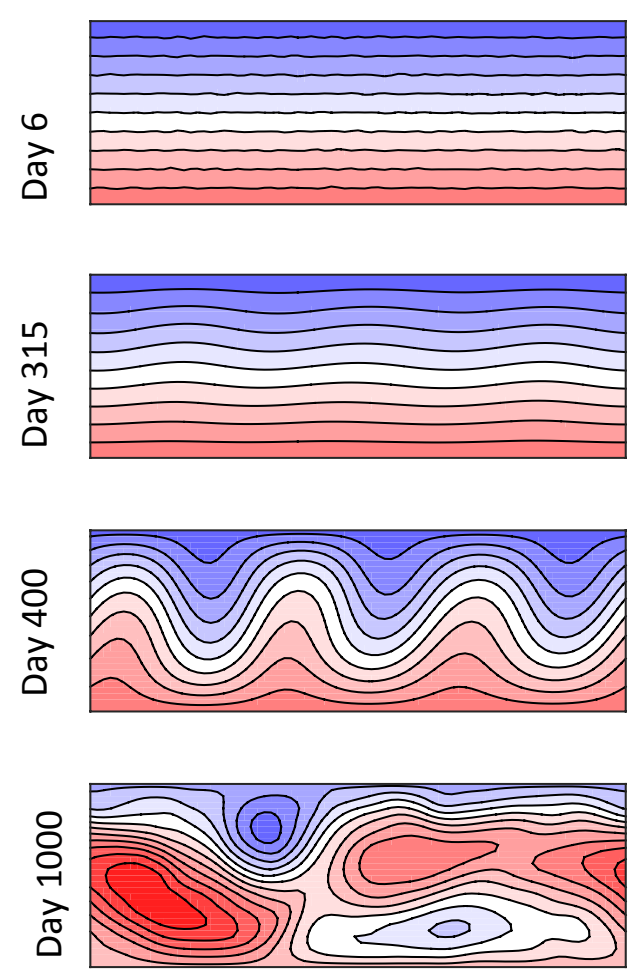

Streamfunction layer 2
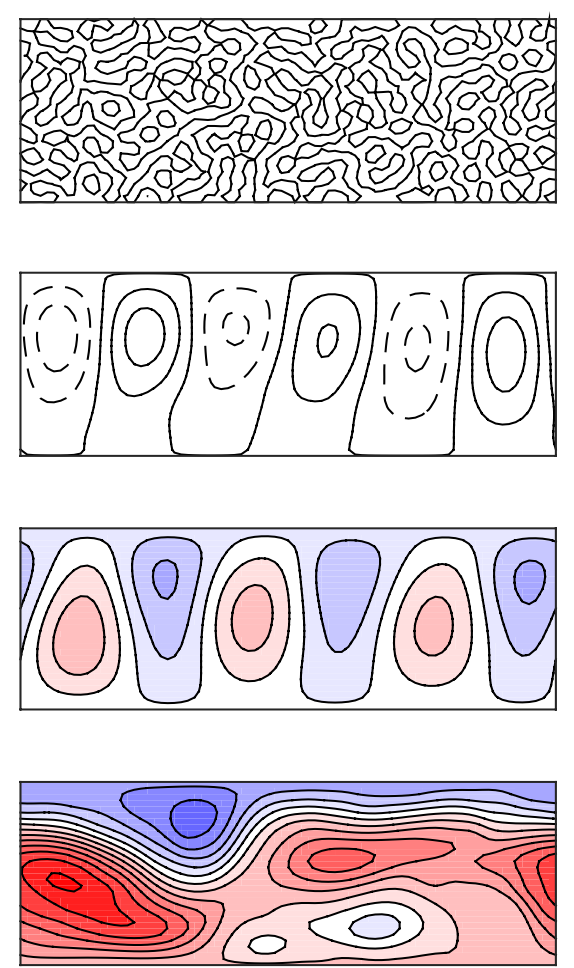

Figure 2: Time evolution of a weakly baroclinically unstable jet in a periodic channel in a two layers QG model. The initial condition is a zonal flow in the top layer and a low amplitude random streamfunction in the lower layer. Initially, the lower layer streamfunction, being much smaller than the upper layer, is displayed by black contours (with a factor of ten contour interval compared with the upper layer). After a year, the perturbation grows and the lower layer flow is dominated by the linearly most unstable wave, with a scale larger than the Rossby radius (the Rossby radius wavelength is $1 / 5$ th the channel length). This is an illustration of the scale selection process which explains the spatial scale of the most energetic structures in the ocean. At longer times, the most unstable wave reaches a large amplitude and has an imprint in both layers. Finally, the finite amplitude perturbation cascades towards larger spatial scales horizontally and becomes quasi-barotropic. Negative values are indicated by the blue color or by dashed contours. Contour interval is $2000 \mathrm{~m}^{2} / \mathrm{s}$, excepted for the lower layer at day 6 and day 315 (contour interval $200 \mathrm{~m}^{2} / \mathrm{s}$ ). 

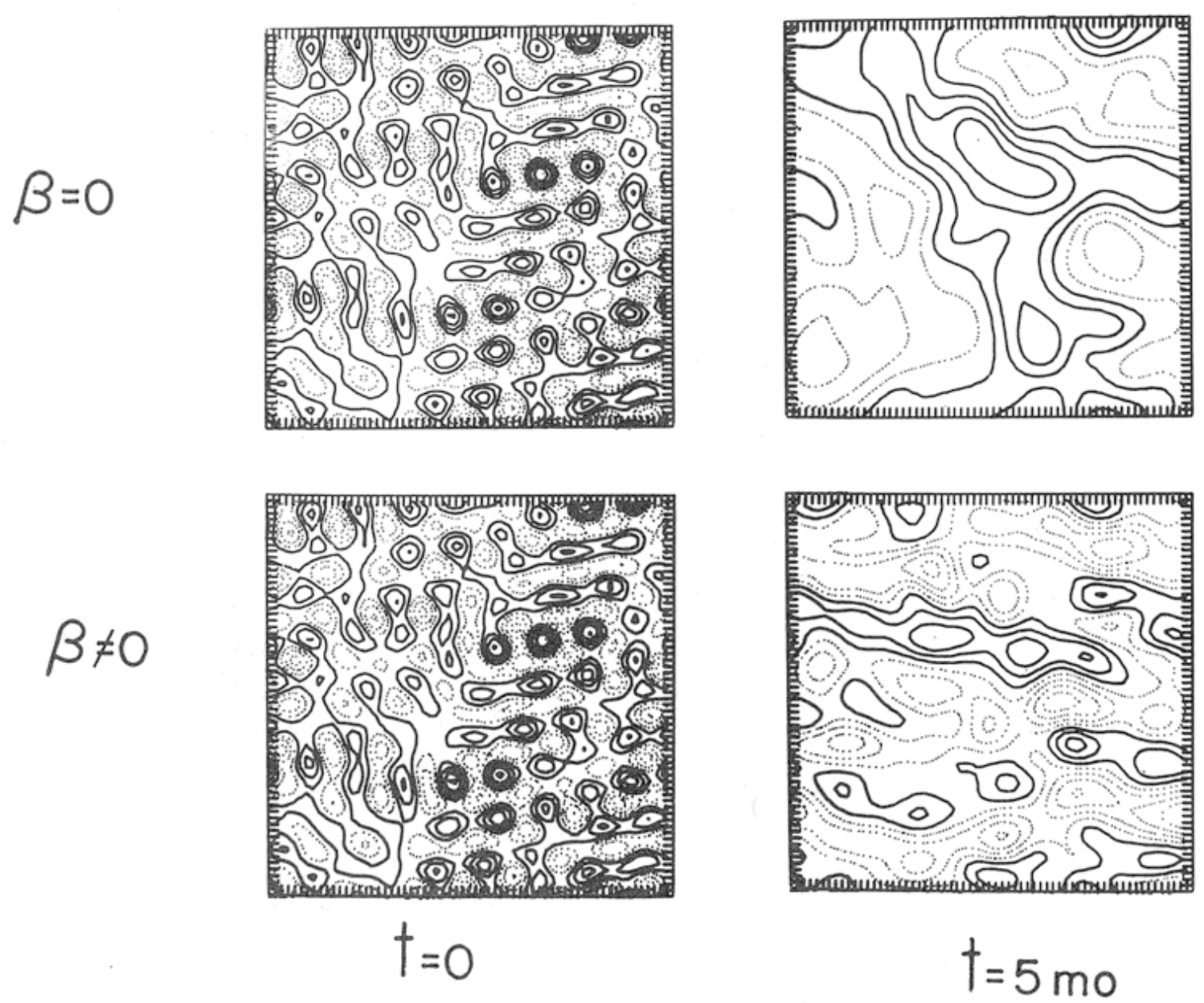

Figure 3: Simulations of barotropic free decaying turbulence (Rhines, 1977). The pseudo-spectral QG model has an equivalent resolution of 64x64 points. It is initialized with a random field (left). After 5 months, the flow evolution of the streamfunction on a f-plane shows the cascade of energy towards large scales, limited only by the size of the domain. On a beta-plane (bottom), the cascade is halted at the Rhines scale and the flow becomes anisotropic with a predominance of zonal currents. Contours for the nondimensional streamfunction are 0.11 at $\mathrm{T}=0$ and 0.16 at $\mathrm{T}=5$. Negative contours are dashed. 

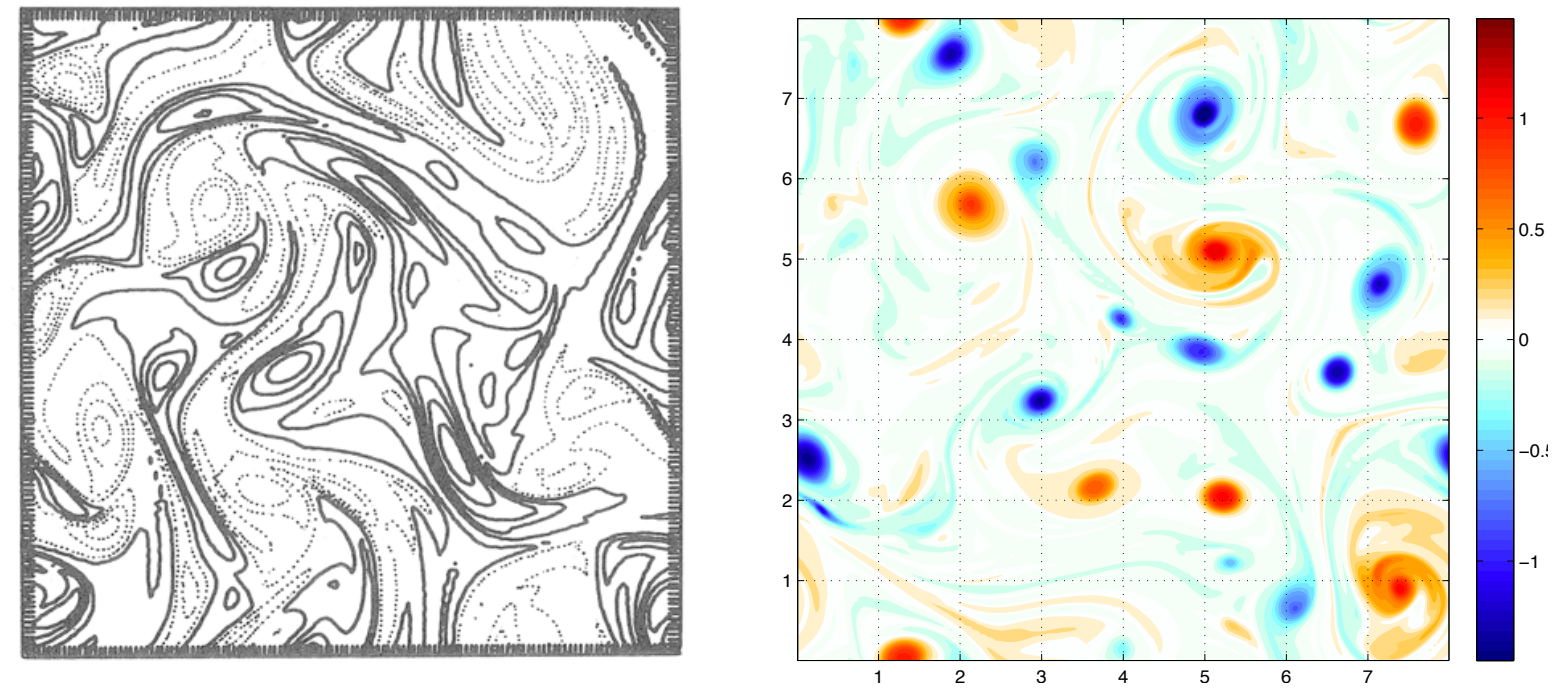

Figure 4 : Vorticity field in free decaying turbulence on a f-plane. a) low resolution barotropic model of Rhines (1977), 64x64 grid points; the vorticity after 5 months is elongated into filaments. b) high resolution simulation of Lahaye and Zeitlin (2012), with $512 \times 512$ points and a domain size of 8 Rossby radius wavelengths. The color scale is in units of vorticity normalized by $f$. Coherent structures appear in the high resolution simulation but not a low resolution. 

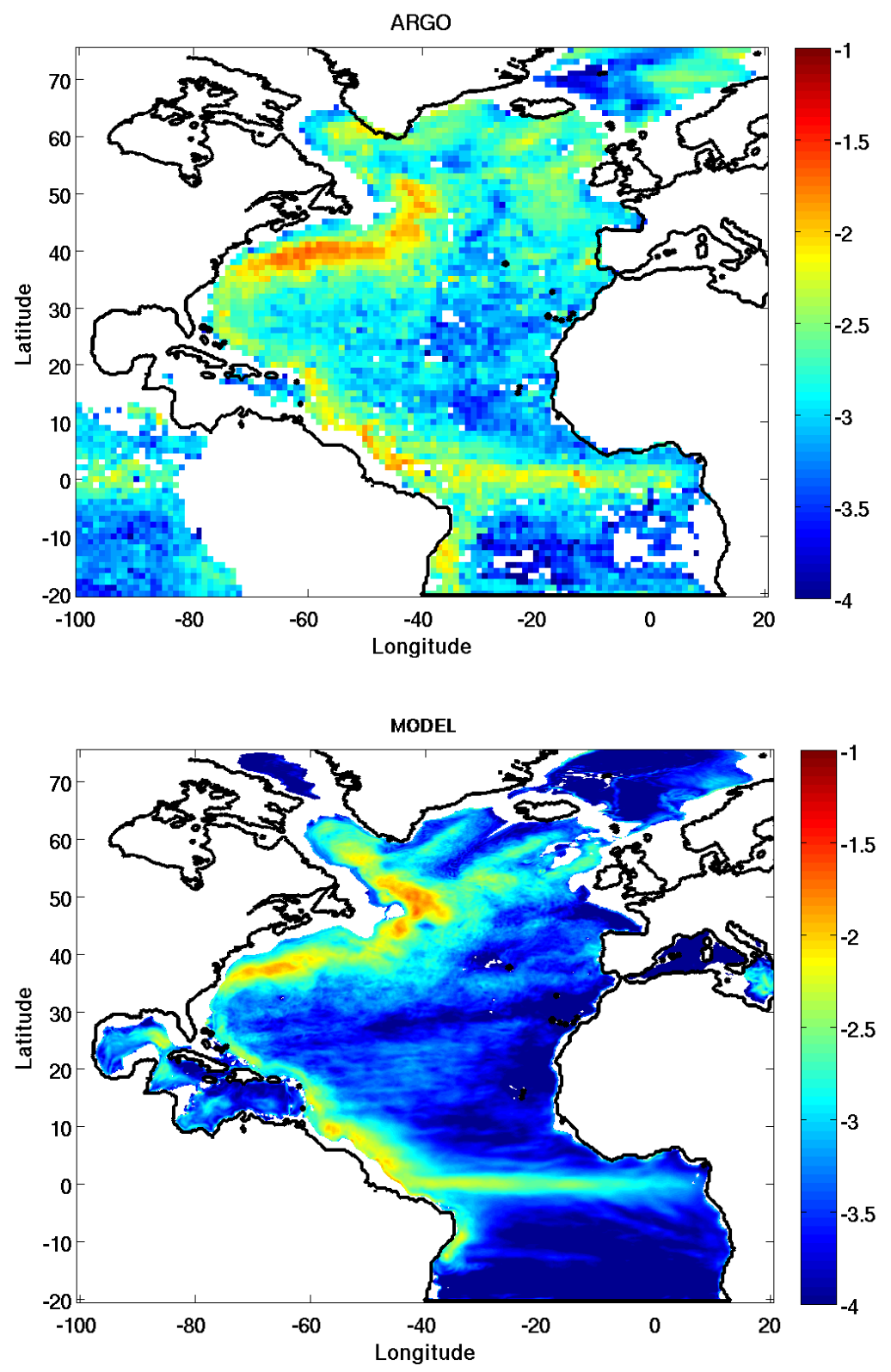

Figure 5: Logarithm of the eddy kinetic energy $\left(\mathrm{m}^{2} \mathrm{~s}^{-2}\right)$ at $1000 \mathrm{~m}$ depth. A): from ARGO floats (Ollitrault and Colin de Verdière, 2014); b) from the North Atlantic $1 / 12^{\circ}$ model. White pixels represent either shallow regions (depth $<1000 \mathrm{~m}$ ) or mission data in the case of ARGO. 
a)

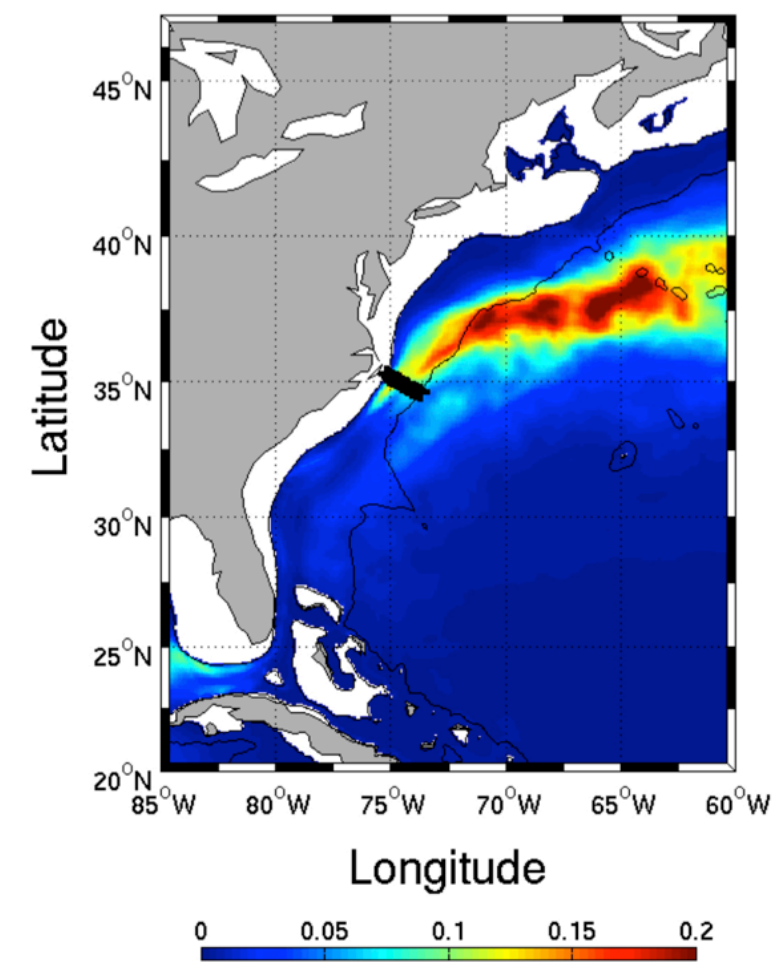

b)

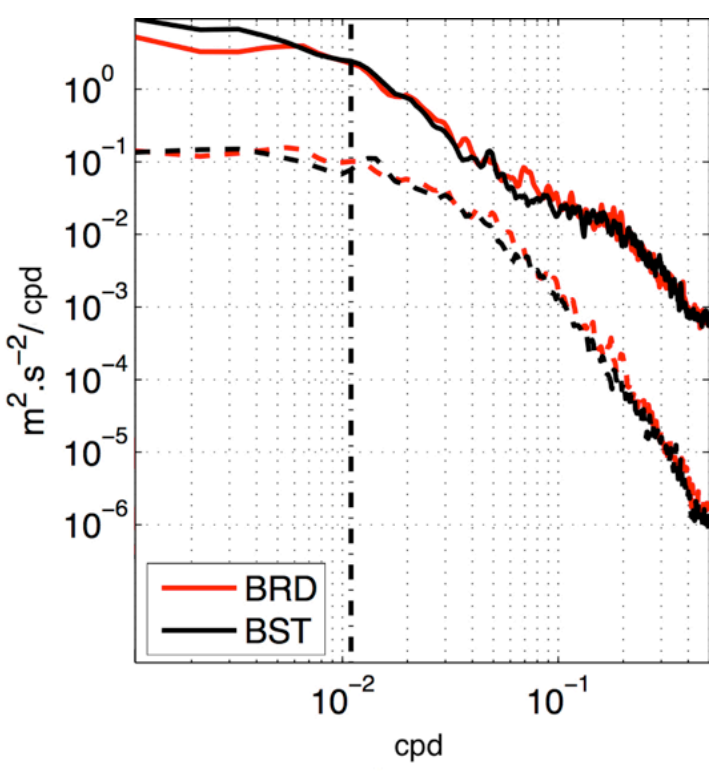

Figure 6: KE distribution at $200 \mathrm{~m}$ depth in the Gulf Stream area from the North Atlantic $1 / 12^{\circ}$ model (a). The frequency spectra (b) represent the EKE distribution on the $35^{\circ} \mathrm{N}$ section from the North Atlantic $1 / 12^{\circ}$ model forced by realistic wind forcing (BRD simulation, red lines) and low frequency wind forcing (BST simulation, black lines) at $200 \mathrm{~m}$ and $2000 \mathrm{~m}$ depth (solid and dashed lines, respectively) 


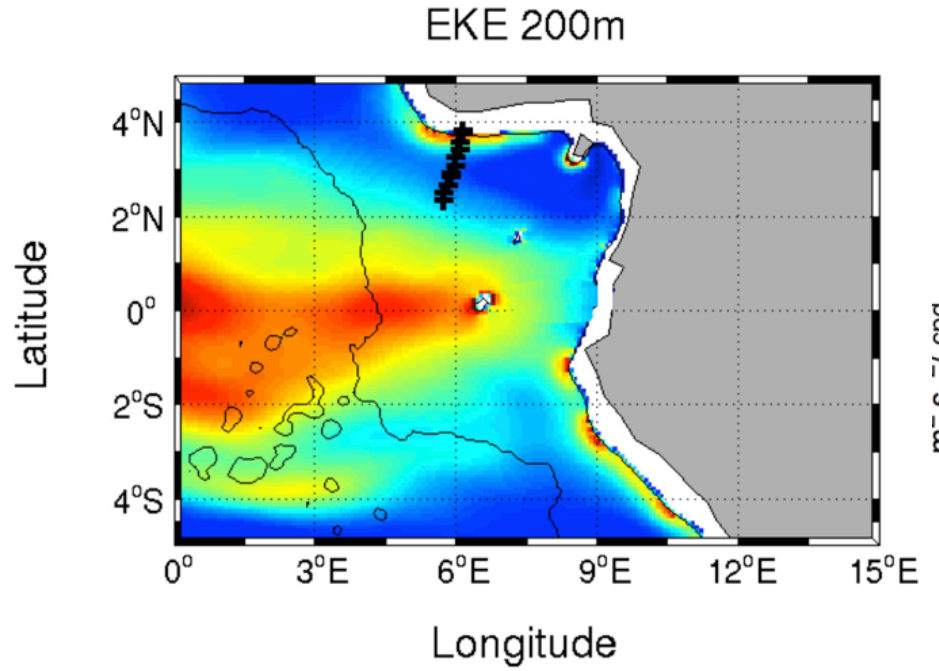

0

4

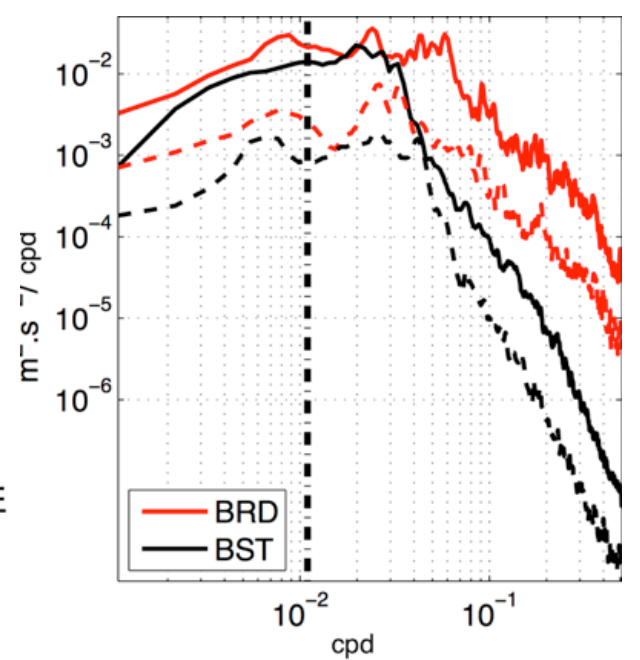

$x 10^{-3}$

Figure 7: KE distribution at $200 \mathrm{~m}$ depth in the gulf of Guinea area from the North Atlantic $1 / 12^{\circ}$ model (a). The frequency spectra (b) represent the EKE distribution on the $4^{\circ} \mathrm{N}$ section from the North Atlantic $1 / 12^{\circ}$ model forced by realistic wind forcing (BRD simulation, red lines) and low frequency wind forcing (BST simulation, black lines) at $200 \mathrm{~m}$ and $2000 \mathrm{~m}$ depth (solid and dashed lines, respectively) 

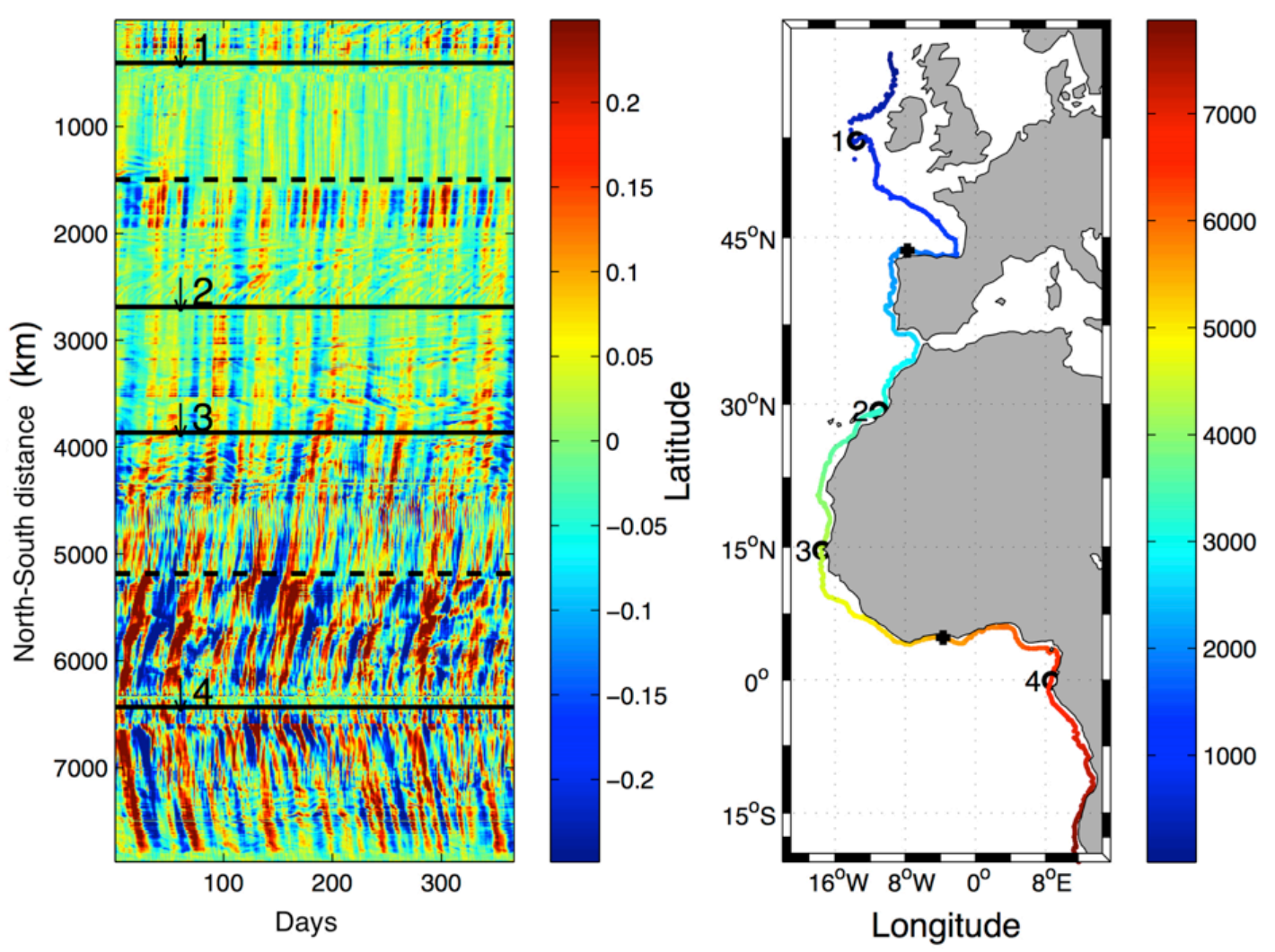

Figure 8: a) Time evolution of the along-shore surface velocity along the continental slope of the Eastern Atlantic (following the $500 \mathrm{~m}$ isobath) from the North Atlantic 1/12 ${ }^{\circ}$ model, for year 1990. The colorbar is in $\mathrm{m} \mathrm{s}^{-1}$. b) Distance following the continental slope in $\mathrm{km}$ from the northern point of the domain. The velocity is high-pass filtered with a cutoff period of 90 days. 

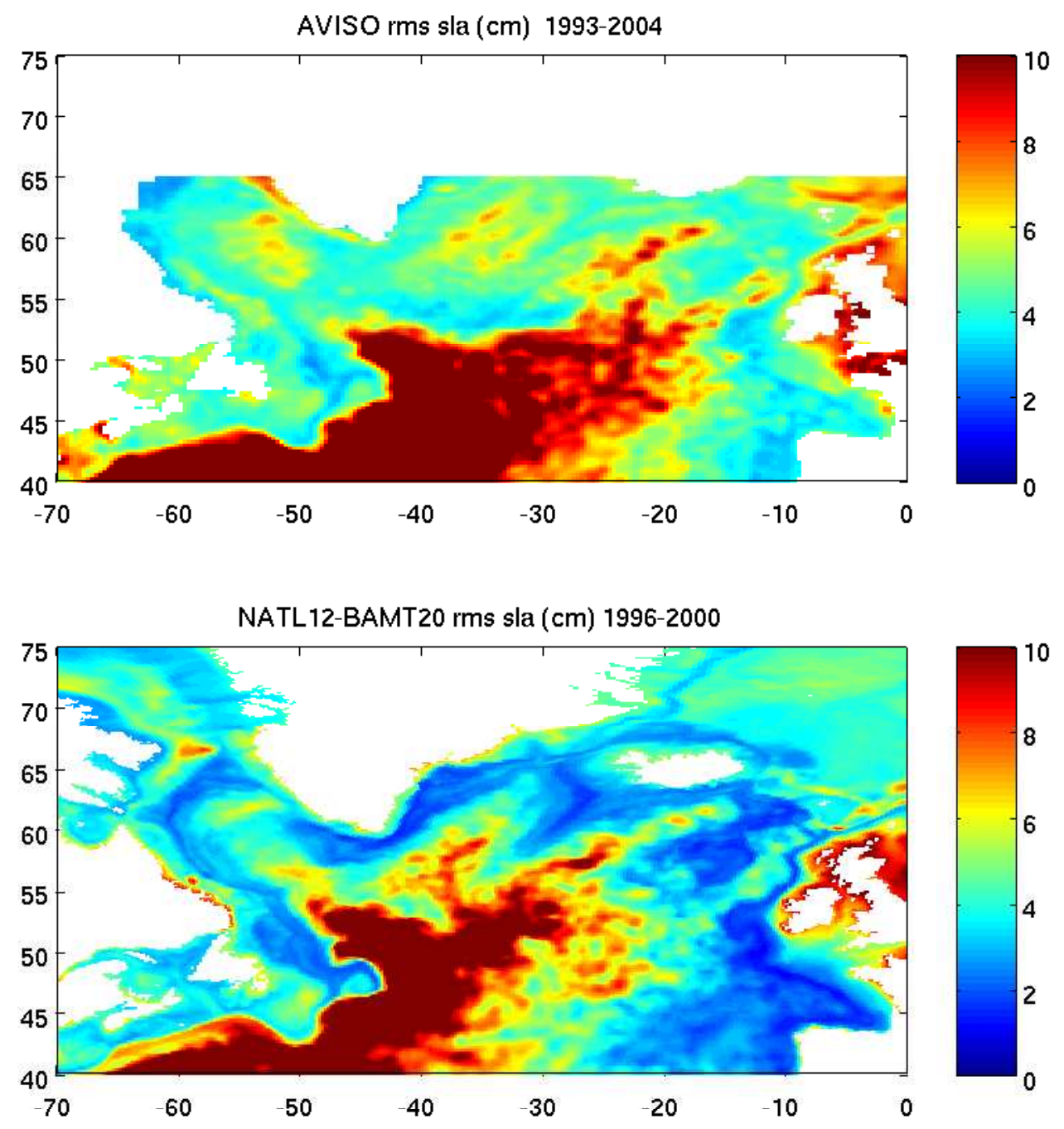

Figure 9: Rms sea surface height anomaly (SSHA, $\mathrm{cm}$ ) from satellite observations (top) and the $1 / 12^{\circ}$ North Atlantic model of Treguier et al (2012). Although the model reproduces well the Gulf Stream path and the North West corner, a spurious branch of the North Atlantic current appears in the subpolar gyre after 1995. This branch entering the Irminger Sea is warm, stratified and baroclinially unstable, and shows up as a filament of high SSHA around $37^{\circ} \mathrm{W}, 57^{\circ} \mathrm{N}$ in the model. This spurious behavior has been found in a few regional and global simulations at $1 / 12^{\circ}$ using the NEMO model; it does not appear at lower resolution $\left(1 / 4^{\circ}\right)$. This demonstrates that large scale circulations in numerical models depends on the representation of mesoscale eddies and flowtopography interactions, which are not robust even at $1 / 12^{\circ}$. 

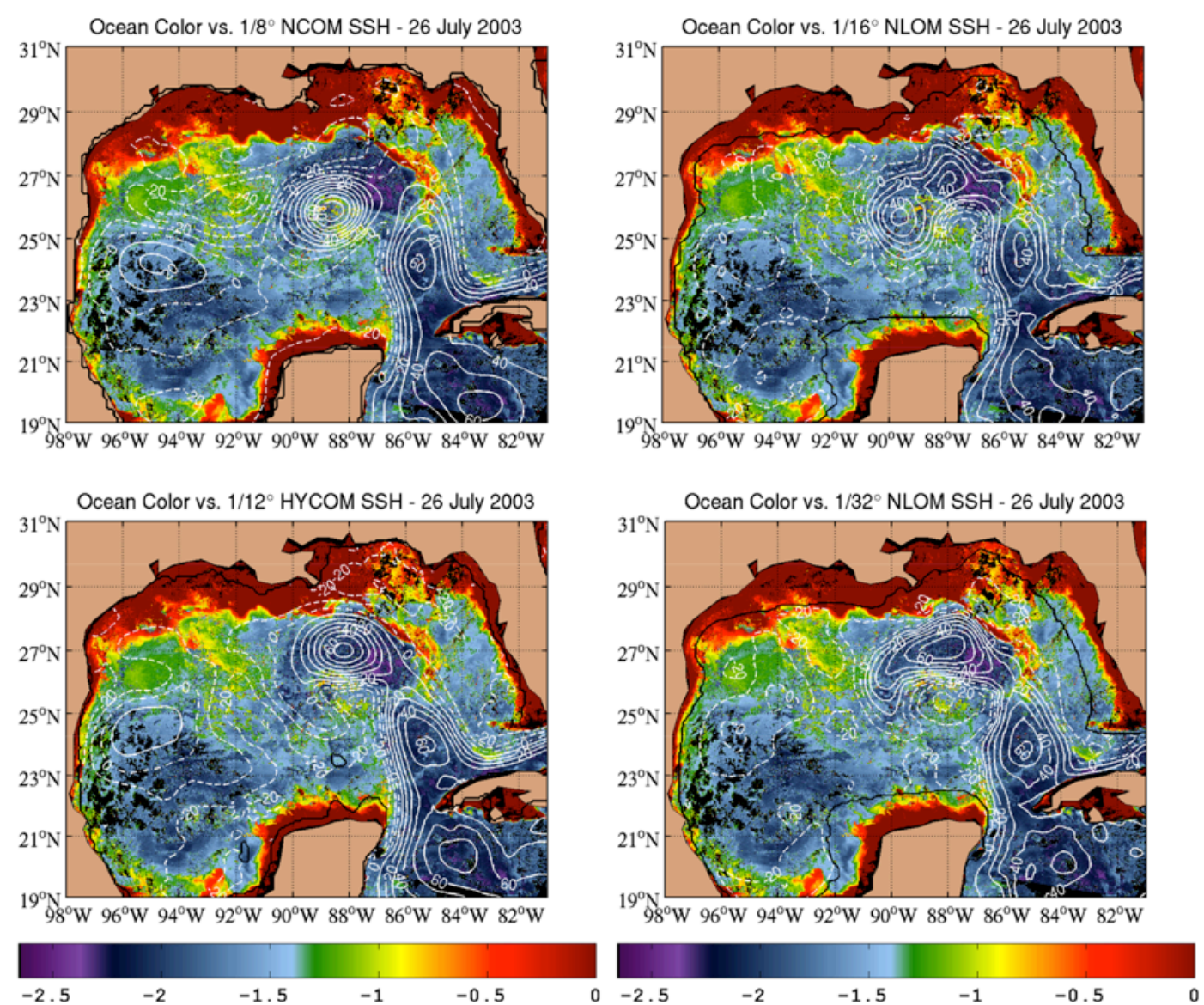

Figure 10: SSH from four ocean data assimilative systems on 26 July 2003 (contour interval of $10 \mathrm{~cm}$ and normalized over the displayed area), overlying ocean color imagery from SeaWiFS (natural log of the concentration in $\mathrm{mg} \mathrm{m}^{-3}$ ). The model land-sea boundary is defined by the black contour line. This figure illustrates the models' ability to represent the Gulf of Mexico Loop Current and associated eddies when compared to the observed SeaWIFS data. The comparison is qualitative, but it clearly shows that resolution is of importance in properly representing the eddies and that SeaWiFS imagery is very effective in differentiating the ability of the systems to map the evolution of the Loop Current and associated warm and cold eddies, and in helping to diagnose specific strengths and weaknesses of the systems.

(From Chassignet et al., 2005). 